Working Paper/Document de travail

2007-52

\title{
Where Does Price Discovery Occur in FX Markets?
}

by Chris D'Souza 
Bank of Canada Working Paper 2007-52

November 2007

\title{
Where Does Price Discovery Occur in FX Markets?
}

\author{
by \\ Chris D’Souza \\ Financial Markets Department \\ Bank of Canada \\ Ottawa, Ontario, Canada K1A 0G9 \\ dsou@bankofcanada.ca
}

Bank of Canada working papers are theoretical or empirical works-in-progress on subjects in economics and finance. The views expressed in this paper are those of the author.

No responsibility for them should be attributed to the Bank of Canada. 


\section{Acknowledgements}

I thank seminar participants at the Bank of Canada, the Eastern Finance Association, the Midwest Finance Association, and the European Financial Management Association meetings for their

comments. I am especially grateful to Greg Bauer, Scott Hendry, Michael King, Ingrid Lo, Stephen Sapp and Wally Speckert for their suggestions. 


\begin{abstract}
Trades in foreign exchange markets are initiated around the world and around the clock. This study illustrates that trades are more informative when initiated in a local country or in major foreign exchange centers like London and New York. Evidence suggests that informational asymmetries based on geography arise from the market making capacity of dealers and the customer order flow that dealers capture during regional business hours. Findings also show that market orders initiated in price-correlated FX markets are not informative. Transparency in quotes on electronic trading platforms may prevent informed participants from exploiting information across FX markets. Overall, these results are robust across different market conditions.

JEL classification: F31, G15

Bank classification: Market structure and pricing; Exchange rates; Financial markets
\end{abstract}

\title{
Résumé
}

Vingt-quatre heures sur vingt-quatre, des opérations de change sont engagées aux quatre coins du monde. L'auteur montre que ces opérations renseignent davantage lorsqu'elles sont amorcées dans un pays dont la monnaie fait l'objet des transactions ou sur une grande place financière comme Londres ou New York. Certains éléments donnent à penser que les asymétries d'information associées aux lieux géographiques s'expliquent par la taille des transactions que peuvent conclure les cambistes et par les flux d'ordres qu'ils parviennent à capter pendant les heures ouvrables dans leur région d'attache. Les résultats obtenus montrent en outre que les ordres au mieux placés sur des marchés dont les prix sont corrélés n'apportent aucune information nouvelle. La transparence des cours indiqués sur les plateformes de négociation électronique peut dissuader les agents bien renseignés d'exploiter sur d'autres marchés des changes leurs informations. Dans l'ensemble, les résultats se vérifient sous différentes conditions de marché.

Classification JEL : F31, G15

Classification de la Banque : Structure de marché et fixation des prix; Taux de change; Marchés financiers 


\section{Introduction}

Recent evidence suggests that certain market participants in the foreign exchange (FX) market are better informed about the future direction of the exchange rate than others. ${ }^{1}$ This paper examines whether information asymmetries exist across geographic regions. Unlike equity markets, where local investors may naturally have more precise information about the business operations of a local company, in FX markets relevant information about the exchange rate is thought to be public and available to all active participants at the same time, irrespective of location.

Findings in this paper suggest that dealers domiciled in a country whose currency is being traded, and those operating in the world's largest FX commercial centers, have superior information about the fundamental or long-run value of the exchange rate. These results are consistent with theoretical predictions that dealers will have better forecasts of the exchange rate as the trading demands of their customers increase. The findings are also sensible given the institutional structure of the FX market. In particular, customer-dealer trading naturally increases during regular business hours. This is especially true in geographic regions in which the currency that is being traded is also a medium of exchange in the real goods sector of the economy. In addition, in order to minimize their transactions costs, customers will direct their trades to dealers that have the largest market making capacity and the lowest spreads.

A market microstructure approach is taken in this paper to account for the flow of information in the FX market. Theoretical models developed in this area suggest that the strategic behaviour of informed and uninformed market participants impacts price dynamics. $^{2}$ More importantly, a number of studies, including Evans and Lyons (2002b) and Payne (2003), provide empirical support for the hypothesis that FX order flow, a measure of buying or selling pressure in the market and a key variable in the microstructure literature, can explain up to two-thirds of the variation in exchange-rate returns. Intuitively, a trader that is worried about losing an informational advantage they currently possess will immediately execute a trade against the prevailing bid or ask quote in the market. In contrast, studies such as Meese and Rogoff (1983) illustrate that standard macroeconomic models of the exchange rate perform poorly in explaining and forecasting exchange rate movements. In the latter group of models, where variables such as interest rates, money supplies, gross domestic product, trade account balances, and commodity prices are the determinants of

\footnotetext{
${ }^{1}$ Bjønnes, Rime and Solheim (2005), Fan and Lyons (2003), Froot and Ramadorai (2002) and Mende, Menkhoff and Osler (2006) find the FX trades of financial institutions to be more informative about exchange rate movements than the trades of non-financial firms.

${ }^{2}$ See Grossman and Stiglitz (1980), Kyle (1985) and Glosten and Milgrom (1985).
} 
the equilibrium exchange rate, cannot typically outperform a random walk in out-of-sample forecast comparisons. The failure of macroeconomic models to account for the process in which information is disseminated in FX markets may be an important factor contributing to their poor performance.

This paper also examines whether informed dealers, also categorized by their location, trade strategically across correlated asset markets. Drudi and Massa (2005) illustrate how informed dealers in the Italian treasury bond market simultaneously place orders in primary and secondary markets in order to take advantage of differences in transparency in the two markets. Findings in this paper suggest that FX traders are not able to exploit private information obtained in one market across markets through their various trading strategies. This result contrasts with evidence from Evans and Lyons (2002a) illustrating that order flow in individual markets is relevant for determining prices in other FX markets.

The empirical literature associated with equities markets demonstrates that geographic location does indeed matter. For example, Hau (2005) analyses the German electronic trading system Xetra and finds that traders located outside Germany generate lower trading profits. In addition, traders located in Frankfurt, the German financial capital, have superior intraday trading profits compared to those of traders located in other German cities. Coval and Moskowitz (2001) find that among U.S. mutual funds, local investments generates a higher average return while Grammig, Melvin and Schlag (2005) and Eun and Sabherwal (2003) both find that the majority of price discovery occurs in the home market of cross-listed stocks.

In FX markets, there is far less evidence to suggest that a trader's geographic location is an important factor affecting performance or price discovery. Covrig and Melvin (2002) find interdealer quotes from Japanese traders lead quotes in the rest of the U.S. dollar/Japanese yen market, while Sapp (2002) finds banks in a number of different European and U.S. locations exhibit price leadership in the U.S. dollar/German mark market. Peiers (1997) finds evidence that Deutsche Bank is relatively more informed about the future direction of the German mark/U.S. dollar exchange rate before the announcement of central bank intervention by the Deutsche Bundesbank. One weakness with these studies is their sole reliance on indicative quotes rather than interdealer limit orders or transaction prices.

U.S. dollar/Canadian dollar, Australian dollar/U.S. dollar, and New Zealand dollar/U.S. dollar bilateral markets are all examined in this paper. ${ }^{3}$ FX analysts have traditionally

\footnotetext{
${ }^{3}$ The abbreviated codes CAD, AUD and NZD will hereafter be used to represent these bilateral exchange
} 
compared the historical performance of the CAD, AUD, and NZD exchange rates with one another. Figure 1 illustrates some similarities in the movements of the three exchange rates over the period studied, October, 2000 and September, 2002. The three relative prices are typically grouped together because primary commodities constitute a significant component of the exports of Canada, Australia and New Zealand. World commodity price movements explain a large share of the terms-of-trade fluctuations in all three economies. ${ }^{4}$

This paper analyses the information content of trades in each region from which they are initiated. Order flow, calculated across all geographic locations, is included in a vector autoregression (VAR) along with exchange rate returns. Two related measures of the information content of trades are then calculated with these estimates. Hasbrouck (1991a,b) argues that any persistent impact of a trade on the price of a security must arise from asymmetric information signaled by that trade. Alternatively, a decomposition of the long-run variance of exchange rate returns across the different trade locations may provide a broader summary measure of the information contained in each individual trade flow.

This study is unique in that it accounts for both the location of each initiated trade and regional business hours simultaneously. The analysis illustrates why it is necessary to break-up the 24-hour day into five separate non-overlapping regional time spans. Specifically, there are important differences in the dynamics of trading and liquidity provision across time and across markets. ${ }^{5}$ Significant intraday correlations in exchange rate returns are also documented in this study. These stylized facts can provide a motive for market participants to speculate across markets. This paper presents evidence that the mechanism by which FX markets interact with one another occurs via exchange rates quotes and not through order flow. In particular, measures of the information content of trades calculated from a vector autoregression model indicate that order flow in one market does not affect exchange rates in another. Overall, the results in this paper are robust to various modelling assumptions and choices of subsamples.

The rest of the paper is organized into seven sections. Section 2 provides a review of

rates and their respective FX markets. The first currency listed in each pair is the base currency. By convention, exchange rates are listed on electronic trading/brokering screens as: USD/CAD, AUD/USD and USD/NZD where USD/CAD is the number of Canadian dollars per U.S. dollar, and AUD and NZD are quoted as AUD/USD, or the number of U.S. dollars per Australian dollar, and NZD/USD, or the number of U.S. dollars per New Zealand dollar. In this paper, conversions are made so that the base currency is always the U.S. dollar.

${ }^{4}$ See Chen and Rogoff (2003).

${ }^{5}$ Payne (2003) illustrates the importance of explicitly accounting for time-of-day effects in the German mark/U.S. dollar market. 
the relevant literature. Section 3 describes the structure of the FX market and the datasets employed in the paper. Section 4 presents descriptive statistics regarding the time-series and cross-sectional aspects of the data. The methodology employed in the study is described in Section 5. Empirical findings related to the price discovery process across geographic locations are presented in Section 6, while results associated with how private information is transmitted across correlated FX markets are presented in Section 7. Finally, Section 8 concludes.

\section{Asymmetric Information across Location and Mar- kets}

Customer-initiated trades, related to the purchases and sales of international goods and services, and the foreign direct and indirect investments of non-dealing organizations, are the catalyst for interdealer trading. Evans and Lyons (2004) argue that individual customer trades contain little pieces of new information about the underlying macroeconomic fundamentals driving the exchange rate. In aggregate, customer order flow can be an important source of information that accrues to dealers, and that subsequently drives interdealer speculation. Asymmetric information in interdealer FX markets may then be driven by differences in the abilities of dealers to capture customer order flow. The hypothesis is tested in this paper.

There are a number of ways that dealers compete for this important source of information. Simply by operating at the same time that potential customers conduct their own business operations, dealers may be able to increase their involvement in customer deals. It is important to note that customers do not necessarily reside in their dealer's geographic location. In the long-run, the ability to offer competitive quotes to customers will be the most important factor determining a dealer's share of customer-dealer trades. The formation of a dealer's quotes will be related to how effectively they manage their inventories and any undesired positions. ${ }^{6}$ D'Souza and Lai (2006) illustrate how market making activities are influenced by the risk-bearing capacity of a dealer, which is itself determined by the amount of risk capital allocated to this activity by each financial institution.

Dealers operating from the largest FX trading centers in the world, such as New York, London and Tokyo, may have a comparative advantage in capturing order flow. Not only are they operating, for the most part, during the core business hours in North America, Europe

\footnotetext{
${ }^{6}$ See O'Hara (1995).
} 
and Asia, respectively, but many international financial institutions devote large amounts of capital to their trading desks in these three locations. It is natural to assume that dealers in these locations will be better informed about expected future changes in exchange rates.

This paper is most similar in scope to Menkhoff and Schmeling (2006) who analyze the importance of local trading in the Russian rouble market. Menkhoff and Schmeling find trades originating in Moscow, and to a lesser extent St. Petersburg, are more informative about the future direction of the Russian rouble/U.S. dollar exchange rate than those initiated in six other economic regions in Russia. There are a number of shortcomings with their study that limit the extent to which its results may be generalized to other markets. The Russian rouble/U.S. dollar market is a very small niche market with turnover equal to only $0.4 \%$ of total world currency trading volume (BIS, 2001). A more serious concern with this study relates to the fact that the dataset examined covers a total period of only 9 trading days.

Recently, it has been recognized that the information content of FX trades in one market may be relevant in the determination of the exchange rate in other markets. For example, Evans and Lyons (2002a) develop a multicurrency portfolio model in which dealers regularly adjust their overall currency portfolio after observing order flow across many currency markets. As with single market models, dispersed bits of information get revealed and aggregated through interdealer trading. In the multiple currency market environment, if customer trades and/or exchange rate returns are correlated, dealers can utilize information about multiple order flows to make inferences about portfolio shifts taking place across markets. Again, while interdealer orderflow is the medium through which information about asset demands becomes impounded into equilibrium prices, it is customer trades, which may be correlated with exchange rate fundamentals, that are private information of dealers, and serve as the source of speculative demands in interdealer trading. Hence, if dealers are able to capture a larger share of these customer dealers across many markets they may generate larger risk adjustment profits. Those traders located in large financial centers have a natural advantage in collecting order flow from multiple currency markets.

Differences in market structures may also lead to situations in which order flow in one market is informative about prices in other markets. Specifically, if exchange rates are correlated, and differences in trade and quote transparency or liquidity exist, traders may have an opportunity to exploit private information across multiple markets. For example, dealers may be able to conceal information longer in an opaque market rather than a transparent one. Alternatively, dealers may instead attempt to exploit an informational advantage in those markets in which the associated costs of trading are lower. Strategies may include 
taking long positions in one market along with partially off-setting short-positions in others. For example, Naik and Yadav (2003) find that dealers in U.K. government bond markets make significant directional bets by holding futures contracts to hedge changes in their spot exposure.

Drudi and Massa (2005) illustrate how informed traders may adjust their usual trading practices in order to exploit their informational advantage in less transparent markets. Dealing banks, participating in the Italian Treasury bond market, are found to exploit private information by simultaneously trading in both primary and secondary markets. In interdealer brokered foreign exchange markets, there are few differences in the level of transparency across markets, but there can be large differences in the levels of liquidity across markets at different times of the day. Trading costs may prevent a trader from exploiting private information in a less liquid market, but not necessarily in a more liquid price-correlated market. If exchange rate returns are correlated, but differences in liquidity persist, dealers may develop multiple market trading strategies that generate larger profits.

\section{FX Market Structure and Data}

The foreign exchange market is the largest financial market in the world. Average turnover in spot transactions, outright forwards and foreign exchange swaps was U.S. \$1.9 trillion in April 2004 - an increase of $57 \%$ over 2001 levels. In the spot market, trades take place between customers and dealers, or just between dealers in the interdealer market. Customers are the financial and non-financial firms that are the end-users of foreign exchange currencies for settling imports or exports, investing overseas, hedging business transactions, or speculating. Interdealer trading accounts for a large share of total trading in the foreign exchange market. In this sphere of the market, trades are executed either directly or via an interdealer broker (IDB) to insure anonymity. Interdealer trading accounts for between $60 \%$ and $80 \%$ of the total volumes of trading in the foreign exchange market (Rime, 2003).

Trading in foreign exchange markets is more decentralized and opaque than in equity markets. Also, unlike equity exchanges with fixed opening and closing hours, trades in the FX market can occur around the clock. In the customer-dealer and direct interdealer segments the market is quote driven while in the brokered interdealer segment a limit order book exists. The best available prices reflect submitted orders from a limit-order book in order driven markets. ${ }^{7}$ Since customers are located in different time zones, trading must be

\footnotetext{
${ }^{7}$ In quote driven markets, the best available prices reflect dealers' quotes.
} 
organized in this decentralized fashion. ${ }^{8}$ Dealers receive private information through customer orders. Each dealer will know their own customer orders through the course of the day, and will try to deduce the positions of other dealers in the market.

Brokers in the FX market display the best bid and offer quotes to the market without revealing the identity of any dealers. Brokers are pure matchmakers and do not take positions. They execute incoming market orders against the best quotes. There are two types of brokers in the FX market, electronic and voice brokers. The two electronic brokers in the interbank market include Reuters (Dealing 3000) and EBS (Electronic Brokering Services). Electronic brokers have taken a significant market share from both voice brokers and direct trading over the past decade. According to Rime (2003) electronic brokers are the main trading channel in the interbank market. ${ }^{9}$ While trading through an electronic broker is anonymous before the trade is executed, after its completion both parties to the trade know the identity of their counterparty.

The CAD, AUD and NZD markets examined in this paper represent 4\%, 5\%, and less than 1\%, of total FX currency volumes, respectively. ${ }^{10}$ Actual transactions are analyzed rather than indicative quotes which are used elsewhere in the literature. The propriety trade data was made available from a large IDB in the FX market. There are a number of advantages from examining the three markets jointly. First, results can be compared across markets over a sample period with similar external market conditions. Second, the three FX markets examined are relatively liquid. Orders are placed throughout the day and around the globe in one geographic location or another. In the Russian rouble/U.S. dollar market analyzed in Menkhoff and Schmeling (2006), trades take place for only one hour a day-from 10:30 to 11:30 Moscow time. Third, while most studies focus on the largest FX markets such as the euro/U.S. dollar or Japanese yen/U.S. dollar markets, given the role of the euro, yen and the U.S. dollar as reserve or vehicle currencies, results may not be comparable across the majority of FX markets operating around the globe.

This dataset includes the exact time (GMT) and date that each market order was executed against the limit-order book. In addition to the transacted exchange rate and the associated trade volume of each trade, the dataset is unique since it discloses the geographic location of the trade-initiator (i.e., the country where the market order was entered into the electronic IDB). This piece of information is necessary to establish whether dealers in one location have

\footnotetext{
${ }^{8}$ The decentralized nature of the market makes regulation difficult.

${ }^{9}$ Dealing 2000-2 was introduced by Reuters in April 1992.

${ }^{10}$ The largest FX markets, U.S. dollar/euro, U.S. dollar/Japanese yen, and U.S. dollar/British sterling, account for $28 \%, 17 \%$ and $14 \%$, respectively, of total trading in all currency markets. (BIS, 2004)
} 
an informational advantage over dealers in another location. The dataset includes all market orders in the CAD, AUD and NZD markets executed on the IDB over the two-year period from October 1, 2000 to September 30, 2002. Trade data is then aggregated into 5-minute intervals. The sampling interval is fine enough to minimize any possible contemporaneous correlation between trades and exchange rate variables in the analysis conducted below. While there are over 30 possible locations (or countries) where trades may be initiated, in most, only a handful of trades are executed per day. The analysis below focuses only on trades initiated in Australia, Canada, Japan, New Zealand, U.K., and the U.S. in each exchange rate market. Australia, Canada, New Zealand and the U.S. are included in the analysis since their own currency is part of at least one of the currency pairs. Japan and the U.K. are included since both Tokyo and London, in addition to New York, have historically been considered large FX commercial centres. ${ }^{11}$

To determine if a trade was executed on the bid or ask side of the market, intraday quote data for CAD, AUD and NZD exchange rates is obtained from Olsen and Associates over the same sample period. The intraday data provide the bid and ask spot rates at the end of every 5 -minute interval over a 24 -hour period for each exchange rate. ${ }^{12}$ To calculate order flow, trades must be categorized as either buyer-initiated or seller-initiated. Trades are signed according to the following rule provided by Lee and Ready (1991): if a transaction occurs above the prevailing mid-quote, it is regarded as buyer-initiated. Otherwise it is designated as a seller initiated trade. If a transaction occurs exactly at the mid-quote, it is signed using the previous transacted exchange rate according to the following tick test: the trade is buyer-initiated if the sign of the last non-zero exchange rate change is positive. Following Hasbrouck $(1991 \mathrm{a}, \mathrm{b})$ trades are signed as +1 if foreign exchange is purchased and - 1 if foreign exchange if sold. ${ }^{13}$ Order flow in each location is then determined by summing-up the signed trades in each 5-minute interval. Midpoints of bid and ask quotes are used to generate a series of exchange rate returns. Returns are continuously compounded returns, defined as 100 multiple by the log difference of the exchange rate determined at the end of each 5-minute interval.

The analysis is completed in Greenwich Mean Time (GMT). Since daylight savings time (DST) has been adopted in Australia, Canada, New Zealand, U.K. and the U.S., the GMT hours corresponding to business hours in some locations shift by one hour twice a year.

\footnotetext{
${ }^{11}$ Data associated with the city centre that trades are initiated from is not available.

${ }^{12}$ Olsen and Associaties (oanda.com) collects quotes from a number of real time data feeds.

${ }^{13}$ Signing the volume of trades is an alternative measure of order flow. Trades are signed +(Trade Volume) if foreign exchange is purchased and -(Trade Volume) if foreign exchange if sold.
} 
Further, in each region, the switch to and from DST is not simultaneous across locations. The paper avoids some confusion by looking only at days in which all DST adopters have switched to or from DST. This subset of days can be grouped into four sub-samples:

(i) October 30, 2000 - March 16, 2001 (No DST)

(ii) April 2, 2001 - October 5, 2001 (DST)

(iii) October 29, 2001 - March 15, 2002 (No DST)

(iv) April 8, 2002 - September 30, 2002 (DST)

National holidays and weekends are also excluded from the dataset. Weekends begin on Fridays at 22:00 GMT and end on Sundays at 22:00 GMT.

\section{Descriptive Statistics}

The foreign exchange market operates twenty-four hours a day. While many papers have characterized the high-frequency dynamics of the exchange rates and trading in U.S. dollar/yen and U.S. dollar/euro markets, there has been relatively little focus on smaller but well-developed markets such as those for the CAD, AUD and NZD. ${ }^{14}$ Trading volumes may be relatively smaller in these markets but absolute amounts are still relatively large. Table 1 reports daily summary statistics for each of the three currency pairs over time sample period from October 30, 2000 to September 30, 2002. Daily exchange rate returns, presented in percentage amounts, are on average not statistically significantly different from zero in all three markets. Unlike many other exchange rate studies, such as Dacorogna et al. (1993), only the AUD exchange rate exhibits fat-tails or a significant degree of excess kurtosis. ${ }^{15}$ Autocorrelation is detected via a fifth-order Box-Ljung statistic. The asymptotic $5 \%$ critical value for this test statistic is 11.07. There is no evidence of autocorrelation in returns at the daily frequency. Realized volatility is calculated as the sum of all intraday 15-minute squared returns. ${ }^{16}$ Volatility across all three currency pairs is autocorrelated across daily data. This stylized fact was documented by Dacorogna et al. (1993).

\footnotetext{
${ }^{14}$ See the recent papers by Cai, Howorka and Wongswan (2006), Ito and Hashimoto (2005) and Melvin and Peiers-Melvin (2003).

${ }^{15}$ Kurtosis for normal distribution is equal to 3 .

${ }^{16}$ Dacorogna et al. (1993) and Guillaume et al. (1995) suggest using samples periods of at least 10 minutes for reliable statistical analysis.
} 
The average number of market orders executed on the electronic brokering system is highest in the AUD market. On an average business day there are about 1,000 trades in the AUD market, slightly more than 800 trades in CAD market, and about 200 trades in NZD market. ${ }^{17}$ The average trade notional size in all three markets is between 1 and 2 million U.S. dollars. There is very little variation in the trade size in each market suggesting that trade size is determined by market convention. Table 2 reports daily volumes initiated across the 6 trading locations analyzed in the paper. ${ }^{18}$ Trading in the CAD market is dominated by trades initiated in Canada, the U.S. and the U.K. These trades make up $75 \%$ of all trades in the CAD market. Trades initiated in the US and UK make up the majority of trades initiated in the AUD and NZD markets while Japan tends to be a small player in each of these markets.

Trading in the foreign exchange market occurs throughout the day. Figures 2 to 5 illustrate the intraday pattern in the number of trades, the trading volume, bid-ask spreads and volatility, hourly, across the 24-hour clock. For each market, graphs account for changes to and from daylight savings time (DST). ${ }^{19}$ The horizontal axis on each graph is GMT time and does not reflect daylight savings. Notice that for the CAD market, the number of trades, trading volumes, and volatility peak after the opening of business hours in North America. As business hours wind down in North America, all three variables fall. Spreads follow a similar but opposite pattern. They fall dramatically with the start of European business hours, and remain low until the end of the North American business day. ${ }^{20}$ In the AUD market, there are at least two peeks in trades, trading volumes, and volatility. These peaks are associated with morning trading in London and New York. A third smaller peak occurs during Asian business hours. A similar pattern is observed for the NZD market. There is a noticeable difference in trading volumes and spreads in AUD and NZD markets. If the two exchange rates are correlated, informed dealers may trade across the two markets to exploit these differences in liquidity.

Since there are times when some financial centers are open while others are closed, it

\footnotetext{
${ }^{17}$ These numbers do not include crossed trades. The direct crossing of limit orders occurs on an electronic brokering system when a limit buy order has a quote greater or equal to a limit sell order. In this case, the brokering system automatically matches the two orders. Crosses make up more than $50 \%$ of trades in the AUD and NZD markets. In the CAD market they represent about $10 \%$ of trades.

${ }^{18}$ The counterparty to each intiated trade could be located anywhere in the world. The information was not available.

${ }^{19}$ Periods of time when some countries have switched to or from DST and others have not yet switched are not included in the analysis of the paper.

${ }^{20}$ When daylight savings time is in effect the graphs have a similar shape, except the pattern described above begins one hour earlier.
} 
may be necessary to analyze exchange rates and trades separately across a variety of distinct time periods during the 24-hour day. Based on an examination of trading volumes initiated around the world, this paper adopts the breakdown of regions proposed by Cai, Howorka and Wongswan (2006) for the U.S. dollar/euro and U.S. dollar/Japanese yen markets. ${ }^{21}$ Periods in which one region's business hours overlap with another's are separated from periods in which only a single region has regular business hours. The five regional time zones are labeled Asia, Asia-Europe, Europe, Europe-North America, and North America. The specific hours for each zone outside of, and during, daylight savings are presented in Table 3. FX trading activity in each geographic location across time zones reflects regular business activity in that location. Related statistics are presented in Table 2. For example, most trades initiated in Australia, Japan and New Zealand occur during Asian hours while most trades initiated in Canada and the U.S. take place during North American hours. Interestingly, a large proportion of U.K. initiated trades occur during the overlapping Asia-Europe and EuropeNorth America time zones.

To illustrate the appropriateness of these choices, a test of exchange rate efficiency across regions is performed. If exchange rates cannot be characterized as a martingale process across regional time zones, each zone should not be analyzed separately. ${ }^{22}$ The methodology of Neumark, Tinsley and Tosini (1991) is utilized. ${ }^{23}$ Empirically, overnight exchange rate movements occurring after the close of business hours in one regional time zone should be an unbiased predictor of the total change in the overnight exchange rate. For example, in the CAD market, if exchange rate changes occurring during European hours are unbiased predictors of overnight changes in North America, the slope coefficient $(\beta)$ in the following regression will be equal to 1.0 :

$$
\begin{gathered}
\left(C A D_{t}^{N . A m e r i c a n O p e n i n g}-C A D_{t-1}^{N . A m e r i c a n C l o s e}\right) / C A D_{t-1}^{N . A m e r i c a n C l o s e}= \\
\alpha+\beta *\left(C A D_{t}^{\text {EuropeanClose }}-C A D_{t-1}^{N . A m e r i c a n C l o s e}\right) / C A D_{t-1}^{N . A m e r i c a n C l o s e}+\varepsilon_{t} .
\end{gathered}
$$

At the close of European hours, the exchange rate should reflect all relevant information released during European hours if the market is efficient.

Tables 4, 5 and 6 present regression estimates for CAD, AUD and NZD markets, re-

\footnotetext{
${ }^{21}$ Ito and Hashimoto (2005) and Melvin and Peiers-Melvin (2003) have similar definitions of business hours in each region.

${ }^{22}$ For example, exchange rates may not reflect new information until liquidity increases and trading costs fall during trading in a subsequent time zone.

${ }^{23}$ Neumark, Tinsley and Tosini (1991) examine after-hours stock prices while Fleming (1997) looks at the overnight U.S. Treasury market.
} 
spectively. Each estimate $(\widehat{\beta})$ provides one piece of evidence regarding the efficiency of each region and each market. Across all three tables, slope coefficients are significantly different from zero at the $1 \%$ level in all three markets. More importantly, regressions reveal that slope coefficients are insignificantly different from 1.0. There is little evidence that exchange rate movements in any one region are not efficient. Consequently, each regional time zone is examined seperately in the analysis to follow.

\section{Empirical Methodology}

This section illustrates an approach widely employed in the literature to determine the informational content of trades and quotes. ${ }^{24}$. The impact of order flow (characterized by the location in which a trade is initiated), or changes in exchange rate quotes (in correlated asset markets), cannot be determined from a single regression. All variables are endogenous, and causality between the different order flows and exchange rates may occur in multiple different directions. For example, while an unexpected purchase of foreign currency by a trader may lead to a change in the exchange rate, the causality may also work in the other direction: an unexpected increase in the exchange rate could influence the purchases of foreign currency. Alternatively, trades initiated in the U.K. may serve as a catalyst for trades initiated in the U.S., while trades initiated in the U.S. may serve as a catalyst for trades initiated in Canada. The methodology of Hasbrouck $(1991 \mathrm{a}, \mathrm{b})$ is robust to modelling assumptions while at the same time it is able to characterize the dynamics in which all types of trades and exchange rate returns interact.

A vector autoregression (VAR) is estimated to determine both the sources of exchange rate variation and whether that variation is permanent or transitory. A VAR is a linear specification in which each variable is regressed against lags of all variables. The model captures the dynamic relationships between all variables. It also allows for lagged endogenous effects. Two different statistics are examined with the estimated VAR: an impulse response function is used to determine the permanent exchange rate impact of each order flow or exchange rate variable, while a variance decomposition is employed to determine the relative importance of all variables in explaining the variation in exchange rate returns.

Theoretically, exchange rates can be thought of as being composed of two elements: an informationally efficient price and a transitory element reflecting frictions in the trading

\footnotetext{
${ }^{24}$ The methodology has been utilized across all financial markets. For example, Hasbrouck (1988, 1991a,b 1993) focuses on U.S. equity markets, Payne (2003) looks at the spot U.S. dollar/German mark exchange rate market, while Chordia et al. (2005) examine linkages between stock and bond markets.
} 
process. While new fundamental information will lead to a permanent revision in the market expectations of the exchange rate, microstructure effects will be short-lived and transient. Specifically, the long-run response of the exchange rate to a trade will depend on whether or not that trade was initiated by an informed trader with private fundamental information. In order for trades to be informative, traders on the passive side of a transaction must be able to update their beliefs regarding the future direction of exchange rates. In an electronic brokering system, limit orders are anonymous, but once a market order is executed, both the initiator and receiver receive information about the identity of their counterparty. Statistically, the extent of asymmetric information in trades can be measured by the explanatory power of each order flow variable in accounting for exchange rate variation. While the transitory effects of a trade may drive the current exchange rate away from the informationally efficient level, over a short period of time these effects will dissipate. The VAR methodology employed below allows for an examination of the relationship between trades initiated in different locations - possibly across markets, and exchange rate returns.

Let $z_{t}$ denote the column vector of all variables,

$$
z_{t}=\left[x_{11 t}, \ldots x_{m n t}, r_{1 t}, \ldots r_{n t}\right]
$$

The variable $x_{i j t}$ is the order flow calculated from trades initiated in the $i$ 'th location in the $j$ 'th market, while $r_{j t}$ is the percentage exchange rate return over the 5-minute interval in the $j$ 'th market.

The VAR specification can be written as:

$$
z_{t}=A_{1} z_{t-1}+A_{2} z_{t-2} \ldots+A_{k} z_{t-p}+\nu_{t}
$$

where the $A^{\prime} s$ are coefficient matrices, $p$ is the maximum lag length, and $\nu_{t}$ is a column vector of serially uncorrelated disturbances (the VAR innovations) with variance-covariance matrix $\Sigma$. Estimates of VAR coefficients and associated variance-covariance matrices can be obtained from least-squares estimation. ${ }^{25}$

VARs are sensitive to lag length, or $p$ in equation (1) above. The Schwartz Information Criterion defined as

$$
S I C=\ln \left|\widehat{\Sigma}_{u}\right|+\frac{k \times \ln T}{T}
$$

is employed to determine the lag length of the VAR, where $k$ is the number of regression co-

\footnotetext{
${ }^{25}$ See Judge et al. (1988) and Hamilton (1994) for a discussion of vector autoregressions.
} 
efficients in the system, $T$ is the sample size, and $\widehat{\Sigma}_{u}$ is an estimate of the residual covariance matrix. The order of the VAR, $p$, is determined by minimizing (2). Impulse response functions represent the expected future values of the system conditional on an initial disturbance, $v_{t}$, and can be computed recursively from equation (1). The vector moving average representation (VMA) provides the elements needed to calculate the impulse response function. The accumulated response function of one variable to a shock in another can be determined from the $\Psi_{k}$ matrices in

$$
E\left[z_{t}+z_{t+1}+\ldots z_{t+k} \mid v_{t}\right]=\Psi_{k} v_{t}
$$

The long-run impact of an innovation on the cumulative exchange rate return measures the fundamental information content of an innovation in a variable. Any persistent impact reflects new payoff relevant information. In terms of the accumulated response coefficients, the cumulative return implied by a particular disturbance may be written as

$$
E\left[r_{j t}+r_{j t+1}+\ldots \mid v_{t}\right]=\Psi_{\infty, r_{j}} v_{t}
$$

where $\Psi_{\infty, r_{j}}$ is the row of $\Psi_{\infty}$ matrix that corresponds to the log exchange rate return in the $j$ 'th market. If the VAR representation is invertible, this may be estimated by $\Psi_{n, r}$ where $n$ is large enough to approximate convergence.

In this paper, hypothetical disturbances will be used to study the impact of particular trades or changes in exchange rate quotes in price-correlated markets. The VAR disturbances may be written as $v_{t}=B u_{t}$, where $u_{t}$ is a vector of mutually uncorrelated structural disturbances, and $B$ is a lower-triangular matrix with ones on the diagonal computed by factoring the VAR disturbance covariance matrix $\Sigma$, subject to the desired ordering of the variables. Since the ordering of variables may affect the results, the analysis below reports the minimum response of accumulated returns to a shock in each trade variable across all possible orderings of the order flow variables in the system.

Unless, traders in one location have a comparative advantage in collecting and processing pertinent information relevant to the future movements of the exchange rate, the effects of a trade should be similar. The hypothesis is tested by comparing the average accumulated price impact implied by the response function corresponding to different trade flow innovations. Impulse response functions of exchange rate returns are computed for each sample subsequent to each trade shock.

If the innovation in the random walk or permanent component of an asset price is denoted as $w_{t}$, its variance, $\sigma_{w}^{2}$, will be a measure of the variation in the permanent component of 
exchange rate returns, and can be computed using the VMA coefficients:

$$
\sigma_{w}^{2}=\operatorname{var}\left(E\left[r_{j t}+r_{j t+1}+\ldots \mid v_{t}\right]\right)=\Psi_{\infty, r} \Omega \Psi_{\infty, r}^{\prime}{ }^{26}
$$

and measures the variation in the permanent component of fundamental returns. The disturbance covariance matrix will not be diagonal, therefore the right-hand side of (3) will typically involve terms reflecting the contemporaneous interaction of the disturbances. Assumptions must be made about the structure of the innovations that diagonalize $\Sigma$. The variance of the random walk component of the exchange rate can be written as

$$
\sigma_{w}^{2}=\sigma_{x_{11}}^{2}+\ldots \sigma_{x_{m n}}^{2}+\sigma_{r_{1}}^{2}+\ldots \sigma_{r_{n}}^{2}
$$

Each variable on the right-hand side reflects an incremental contribution relative to the variables that precede it in the ordering. For example $\sigma_{x_{i j}}^{2}$ corresponds to the incremental contribution of the $i^{\prime}$ th order-flow variable in the $j^{\prime}$ th market . The incremental explanatory power of each is measured by adding the variables sequentially to the specification. Relative contributions of each trade and exchange rate return variable to explaining the total variance in the random walk component of exchange rate returns are calculated by dividing these values by $\sigma_{w}^{2}$, so that

$$
1=\frac{\sigma_{x_{11}}^{2}}{\sigma_{w}^{2}}+\ldots \frac{\sigma_{x_{m n}}^{2}}{\sigma_{w}^{2}}+\frac{\sigma_{r_{1}}^{2}}{\sigma_{w}^{2}}+\ldots \frac{\sigma_{r_{n}}^{2}}{\sigma_{w}^{2}}=R_{x_{11}}^{2}+\ldots R_{x_{m n}}^{2}+R_{r_{1}}^{2}+\ldots R_{r_{n}}^{2}
$$

Again, as with impulse response functions, the ordering of variables may affect the values of this summary statistic. In particular, placing a variable earlier in the ordering will increase its information share. Only the minimum variance decompositions across all possible orderings of the variables are reported.

\section{Price Discovery across Geographic Locations}

In this section, the informativeness of trades across locations is examined. VARs are estimated for each regional time zone, across the trading day, in each currency market. Estimated coefficients are not reported. Instead, two summary measures of trade informativeness are presented and discussed: the long-run accumulated impulse response of each order flow on exchange rate returns and the variance decomposition of returns at a long-run horizon. ${ }^{27}$ If trades have a differential long-run impacts on exchange rates, they must reflect private infor-

\footnotetext{
${ }^{26}$ See Hasbrouck (1991b) for an explict derivation.

${ }^{27}$ Twenty 5 -minute periods, or equivalently 100 minutes, is found to be sufficient.
} 
mation and, more generally, the comparative advantage that some dealers have in collecting and processing flows in the market. Impulse response functions are computed subsequent to a standardized innovation in each trade variable.

There are few Canadian-initiated trades during Asian and Asian-European hours, and very few New Zealand-initiated trades during European, European-North American and North American hours. Canadian and/or New Zealand order flow may be omitted in the VAR specification to ensure that non-singular matrices are constructed prior to the VAR regression analysis. Intraday hourly exogenous dummies are added to each equation of the vector autoregression model to account for intraday seasonality. ${ }^{28}$ In general, across all markets and regional subsamples, one, two or three lags minimize the Schwarz information criterion.

Table 7 characterizes the information content of trades in CAD (Panel A), AUD (Panel B), and NZD (Panel C) markets. ${ }^{29}$ Since the ordering of each VAR may impact on the results, all possible orderings of the order flow variables are considered. ${ }^{30}$ The lowest long-run cumulative exchange rate impact is reported for each trade innovation, in each region. Impulse response functions are presented in terms of percentages (e.g., 0.10 represents a $0.10 \%$ long-run change in the exchange rate). A parametric bootstrap procedure (1,000 replications) is used to calculate standard errors for both impulse responses and variance decompositions. To make the exposition clearer, summary measure estimates are not reported if they are not significant at the $5 \%$ level. In general, if a country has regular business hours during the regional time zone examined, then trades in that country have a statistically significant effect on exchange rate returns. ${ }^{31}$

Impulse response results are listed in the upper half of each panel. The largest impact on the CAD exchange rate occurs from Canadian, U.K, and U.S. initiated trades. The size of the impact is largest during normal business hours in each country. A buyer-initiated trade

\footnotetext{
${ }^{28}$ See Payne (2003) for evidence in the FX market.

${ }^{29}$ Results (not reported) are similar if orderflow is defined as the volume of buyer-initiated trades less the volume of seller-initiated trades. Since trades are usually executed in conventional amounts (e.g., \$U.S. 2 million in the $\mathrm{CAD}$ market) there will be little difference in the information contained in trades or trade volumes.

${ }^{30}$ Lows and highs (not reported) are of similar magnitude suggesting that ordering does not matter in the specification of the model. The sampling of trades and exchange rate returns data at 5-minute intervals may have created this favorable effect.

${ }^{31}$ Likelihood ratio tests indicate that the relationship between order flows and exchange rates depends on the regional business hours examined. VARs are estimated across all 24 hours of each day, and included both intercept and slope dummies for regional business hours. In all cases, the hypothesis that intercept and slope dummies are equal across regional business hours is rejected. The result is consistent with estimating separate VARs on data across each regional time zone.
} 
innovation by a Canadian trader has a long-run effect of at least $0.65 \%$ on the CAD exchange rate during North American hours. In contrast, U.S. trades, during these same hours, have a $0.41 \%$ impact on the CAD exchange rate while U.K. trades, during European hours, have a $0.75 \%$ long-run effect. During Asian hours, Australian and Japanese trades have a smaller influence. Interestingly, the U.K. trade effect is much larger before the start of the North American day when Canadian and U.S. traders begin to make markets.

The variance decomposition results listed in the bottom half of each panel mirror the qualitative results of the impulse response functions. This is comforting since the two measures attempt to capture similar aspects. During Asian hours, Australian and Japanese trades explain about $10 \%$ and $7 \%$, respectively, of the variation in the CAD exchange rate. During the Asian-European and European regional time zones, U.K. trades explain more that $40 \%$ of the variation in the exchange rate. Once North America opens up for trading, Canadian and U.S. trades explain more than $60 \%$ of the variation in the exchange rate. Interestingly, Canadian trades are unambiguously more informative than U.S. trades during North American hours. Since empty spaces in the table reflect summary measure estimates that are not statistically significant at the $5 \%$ level, there is insufficient evidence to reject the null hypothesis that trades initiated from these locations are uninformative.

AUD market results are similar to those presented for the CAD market. Australian trades, rather than Canadian trades, have a significantly larger impact on the AUD exchange rate than U.S. and U.K. trades initiated during each country's regular business hours. An Australian initiated trade during Asian hours has a permanent impact of at least $1.18 \%$ on the AUD exchange rate. In contrast, a U.K. initiated trade during European hours has a long-run effect of at least $1.04 \%$ while a U.S. trade during North American hours has an effect of around $0.96 \%$. Overall, these are the largest effects of trade initiated in the AUD market outside of Asian hours. The variance decomposition of AUD returns illustrate that U.K. trades explain more than $50 \%$ of the variation in the exchange rate during European hours, while U.S. trades explain about $25 \%$ of the variation during European-North American and North American hours. Notice that while Japanese and U.K. trades have similar effects on the AUD during Asian hours, Japanese-initiated trades have a significantly smaller effect during the Asia-European overlapping period.

Given the above results, it is not surprisingly that New Zealand trades during Asia hours have the largest impact on NZD exchange rate. A New Zealand-based trade during Asian hours has at least a 2.24\% long-run effect on the NZD exchange rate. As with AUD markets, U.K. initiated trades in the NZD market are most informative during European hours, while 
U.S. initiated trades are most informative during North American hours. Remarkably, New Zealand trades explain only about $7 \%$ of the variation in the NZD during Asian hours while U.K. trades explain nearly $40 \%$ of the variation in the NZD during European hours. Across the three market, results suggest that a home country bias exists in terms of the magnitude of the effect of a local trade on the exchange rate. The exception is U.K.-initiated trades. During European hours, U.K. trades have a larger impact on all FX markets. This result is consistent with the perception of London as the world's dominant FX commercial centre.

Table 7 also provides evidence that there are strong time-of-day effects associated with informational content of trades. In particular, the long-run impact of a trade will depend on which financial centers are operating at that moment of time in the day. Generally, trades have the largest long-run price impact during each country's regular business hours. This coincides with regular market making operations, and the time period in which dealers are best able to capture informative orders from customers and other dealers. Notice also that trade informativeness is smaller at the opening and closing of a region's regular business hours. For example, in all three markets, U.K. initiated trades are less informative during the overlapping hours before and after core European business hours.

Robustness checks are presented in Tables 8 and 9. Payne (2003) finds the information content of orderflow to be related to the supply of liquidity in the market. For each currency pair and for each regional time zone, the top $25 \%$ most volatile days and the $25 \%$ lowest trading activity days are selected. ${ }^{32}$ The same analysis conducted above is performed with these restricted samples. Findings are qualitatively similar. ${ }^{33}$ In particular, none of the results discussed above change significantly. There were a few interesting patterns. In particular, on highly volatile days, in CAD, AUD and NZD markets, Australian and Japanese trades during Asian hours, U.K. trades during European hours, and Canadian trades during North American hours were more informative relative to the whole sample. This was not the case for U.S. trades during North American hours. On the lowest trading days, a similar but opposite effect occurs in CAD and NZD markets. Intuitively, market makers on low volume days are not able to capture as many trades, which may reduce the accuracy of their exchange rate forecasts.

\footnotetext{
${ }^{32}$ More than $50 \%$ of the high volatile days coincide with the release of macroeconomic news announcements.

${ }^{33}$ Results are also similar across all other quartiles. These tables are available from the author.
} 


\section{Price Discovery across Markets}

The same framework employed above is now used to determine if informed dealers trade strategically across FX markets. Exchange rate returns and individual order flows, including those from other markets, are included in a vector autoregression to determine whether crosscurrency trade flows are informative. Correlations in exchange rate returns are presented first to illustrate that a necessary condition exists for traders to speculate across markets. This section also replicates the regression analysis of Evans and Lyons (2002a) to demonstrate that the apparent effect of cross-market order flow on exchange rate returns are not unique to that study. The main contribution of this section is to show that cross-currency order flows are not necessarily informative. Rather, they are correlated with exchange rate returns in their own bilateral market. Evidence suggests that the placement of limit orders in pricecorrelated markets, and not cross-market order flow, are the essential factor driving the price discovery process.

A number of theories discussed earlier predict that cross-market order flow can be informative if exchange rates are correlated. Table 10 documents the daily correlation between CAD, AUD and NZD exchange rates returns in each regional time zone. Most correlation coefficients are statistically significant at the $5 \%$ level. The correlations between CAD and AUD exchange rates, and between CAD and NZD exchange rates, during Asian hours are the only exceptions. In general, correlations are positive, and in the case of AUD and NZD exchange rates, relatively large across all regional time zones, ranging from $0.69 \%$ to $0.74 \%$. Given large differences in trading volumes and spreads in AUD and NZD markets at various times of the day (Figures 2 to 4), informed traders may choose to trade one currency rather than the other for the sole purpose of minimizing execution costs. Interestingly, Table 10 also illustrates positive and statistically significant correlations between aggregate order flow in AUD and NZD markets across all regional times zones.

Tables 11, 12 and 13 present coefficient estimates from single equation regression models in which daily CAD (Table 11), AUD (Table 12) and NZD (Table 13) returns are regressed on aggregate order flows in CAD, AUD and NZD markets. To illustrate the contribution of cross-market order flow, estimates from regressions of returns solely on their own order flows are also provided across all time zones. In AUD and NZD markets, the inclusion of cross-market order flows increases the explanatory power of each equation substantially, with one or both cross-market order flow variables found to be statistically significant. CAD order flow is significant across Asian and European hours in both markets, while AUD and NZD

order flows are significant in each other's market in nearly all regional time zones. Generally, 
results indicate that cross-market order flows may be informative to dealers. ${ }^{34}$ In contrast, results are not particularly strong in terms of CAD returns, with or without cross-market order flow. There is an overall increase in the explanatory power of each regression model with the inclusion of cross market order-flows, but the absolute change is small.

Since exchange rates and order flow are endogenously determined in equilibrium, it is necessary to allows for interdependencies between these variables. ${ }^{35}$ To explore the possibility of cross-market relationships, a set of VAR models is estimated that includes aggregate order flows in each of the three markets, plus all three exchange rate return series. Since best bid and ask quotes are transparent in FX interdealer markets, the specification allows for the possibility that dealers may only adjust quotes across markets after observing changes in bilateral exchange rates. ${ }^{36}$

Table 14 presents impulse response functions and variance decompositions of exchange rate returns in each market. As before, both summary measures give a similar picture. Results indicate that order flow in each bilateral market is the most informative variable across all regional time zones. In the AUD market, AUD order flow explains more than $49 \%$ of this variation, while in the NZD market, the percentages vary between $9.7 \%$ and $30.7 \%$, depending on the region in question. With the exception of Asian hours, CAD order flow explains upwards of $60 \%$ of the long-run forecast variance in CAD exchange rate returns. Surprisingly, cross-market order flows are not statistically significant, except in the case of the AUD market, where CAD order flow is slightly informative during the Asia-Europe regional time zone. Once bilateral market order flow is disaggregated by geographic location, very similar results are found as those presented earlier in Table 7. Specifically, there is a home country upward bias in terms of the magnitude of the effect of a local trade on the exchange rate. Also, during European hours, U.K. trades have a larger impact on all FX markets. ${ }^{37}$

Interestingly, exchange rate returns is other markets are informative, especially in AUD and NZD markets. Usually, cross exchange rate returns explain up to $10 \%$ of the long-run forecast variance in bilateral exchange rate returns. While only AUD returns are relevant in the CAD and NZD markets, both CAD and NZD returns are statistically significant in the AUD market. Specifically, changes in the NZD exchange rate are important across Asian

\footnotetext{
${ }^{34}$ Similar results are found in estimates using data sampled at higher 5-minute frequencies.

${ }^{35}$ Danielsson and Love (2006) discuss the possibility of feedback from order flow to exchange rate returns.

${ }^{36}$ Theory suggests that informed dealers prefer market orders while uninformed utilize limit orders. See Bloomfield, O'Hara and Saar (2005) for a discussion of the choice between market and limit orders.

${ }^{37}$ These dissaggregated VAR estimates, and the associated impulse response functions and variance decompositions of exchange returns, are available from the author.
} 
and European hours, while changes in the CAD exchange rate are relevant across European and North American hours.

The hypothesis that cross-market order flow is informative can be rejected. In particular, traders are not able to exploit any informational advantage they may have across interdealer FX markets. Exchange rates are affected by the dynamics taking place in correlated markets, but the effect is more direct with links between limit order books. Dealers may find it difficult to find profitable trading strategies to utilize information discovered in one market across in other markets given the amount of quote transparency in interdealer brokered markets. Once dealers adjust their limit orders in one market, this information is partially reflected in other correlated markets.

\section{Summary, Conclusion and Future Work}

This paper finds evidence to support the hypothesis that local traders in FX markets are better informed about the future direction of the exchange rate. Further, those dealers operating from within the largest FX commercial centers, such as the U.K. (London) and the U.S. (New York), though not Japan (Tokyo), are also asymmetrically informed, at least during their regular business hours. Specifically, the results of this paper suggest that trades initiated in Canada, the U.S. and the U.K. are the most informative in the CAD market. In the AUD market, trades initiated in Australia, the U.S. and the U.K. are important, while in the NZD market, trades initiated in New Zealand, the U.S. and the U.K. are relevant. In the CAD market, Canadian trades are found to be more informative than U.S. trades during North American hours.

There is a belief that since traders around the world have access to similar real-time news feeds, trades initiated in one location cannot be more informative than trades initiated in another. That hypothesis is rejected in this paper. Overall, results point to a dealer's choice of location and hours of operation as the factors driving informed interdealer trading. Trades initiated during non-business hours, or from 'alternative' locations, may be less related to fundamentals and more related to temporary demands for liquidity.

The results of the paper suggest that even though FX markets operate 24-hours a day, it is important to account for the fact that dealers in each region have regular business hours. Future work should examine in greater depth the exchange rate response to trades occurring during the overlapping period between regional business hours, and more specifically how the joint dynamics in these variables respond to opening and closing hours. Anecdotal evidence 
suggests that FX traders 'close-out' their position at the end of the day. A structural model of exchange rate determination is needed to disentangle liquidity and information effects.

Theoretically, as long as asset returns are correlated across markets, order flow in a given currency may be relevant not only for pricing that currency, but also for pricing of other currencies. Results suggest that earlier findings about the informativeness of cross-market order flows are misleading. Traders are not able to exploit information across interdealer FX markets through the execution of market orders. While exchange rates are indeed affected by exchange rate dynamics in correlated markets, the effect occurs directly through the posting of limit orders. Dealers may find it difficult to utilize information collected from one market in other markets because the best quotes in FX markets are transparent to all market participants. Once dealers adjust their limit orders in one market, this information is nearly instantaneously reflected in other correlated markets. Further research should focus on the link between correlated FX markets, and the transmission mechanism by which information is transferred across other bilateral markets. 


\section{REFERENCES}

Anderson, T., T. Bollerslev, F. Diebold and C. Vega. 2003. "Micro effects of macro announcements: Real-time price discovery in foreign exchange." American Economic Review 93, 38-62.

Bank for International Settlements. 2002. "Triennial central bank survey: Foreign exchange and derivatives market activity in 2001." Bank for International Settlements Press and Communications.

Bank for International Settlements. 2005. "Triennial central bank survey: Foreign exchange and derivatives market activity in 2004." Bank for International Settlements Press and Communications.

Bloomfield, R., M. O'Hara and G. Saar. 2005. "The make or take decision in an electronic market: Evidence on the evolution of liquidity." Journal of Financial Economics 75, 165-199.

Bjønnes, G. and D. Rime. 2005. "Dealer behavior and trading systems in foreign exchange markets." Journal of Financial Economics 75, 571-605.

Bjønnes, G., D. Rime and H. Solheim. 2005. "Liquidity provision in the overnight foreign exchange market" Journal of International Money and Finance 24, 177-198.

Breedon, F. and P. Vitale. 2005. "An empirical study of liquidity and information effects of order flow on exchange rates." mimeo, Imperial College London.

Cai, F., E. Howorka and J. Wongswan, 2006. "Transmission of volatility and trading activity in the global interdealer foreign exchange market: Evidence from Electronic Brokering Services (EBS) data." Board of Governors of the Federal Reserve System working paper 863.

Cao, H., M. Evans, and R. Lyons, 2006. "Inventory information." Journal of Business 79, 325-364.

Chen, Y. and K. Rogoff, 2003. "Commodity currencies." Journal of International Economics $60,133-160$.

Chordia, T., A. Sarkar, and A. Subrahmanyam , 2005. "An empirical analysis of stock and bond market liquidity." Review of Financial Studies 18, 85-129. 
Coval, J. and T. Moskowitz. 2001. "The geography of investment : Informed trading and asset prices." Journal of Political Economy 109, 811-841.

Covrig, V., and M. Melvin. 2002. "Asymmetric information and price discovery in the FX market: Does Tokyo know more about the yen?" Journal of Empirical Finance 9, 271-285.

Dacorogna, M., U. Muller, R. Nagler, R. Olsen and O. Pictet. 1993. "A geographical model for the daily and weekly seasonal volatility in the foreign exchange market." Journal of International Money and Finance 12, 413-438.

Daníelsson, J., R, Love. 2006. "Feedback trading." International Journal of Finance and Economics 11, 35-53.

Drudi, F., M. Massa. 2005. "Price manipulation in parallel markets with different transparency" Journal of Business 78, 1625-1658

D'Souza, C., and A. Lai. 2006. "The effects of bank consolidation on risk capital allocation and market liquidity" Journal of Financial Research 29, 271-291.

Evans, M. and R. Lyons. 2002a. "Order flow and exchange rate dynamics." Journal of Political Economy 110, 170-80.

Evans, M. and R. Lyons. 2002b. "Informational integration and FX trading." Journal of International Money and Finance 21, 807-831.

Evans, M. and R. Lyons. 2004. "Exchange rate fundamentals and order Flow." U.C. Berkeley and Georgetown University working paper.

Eun, C. and S. Sabherwal. 2003. "Price discovery for international traded securities: Evidence from the U.S.-listed Canadian stocks." Journal of Finance 58, 549-576.

Fan M. and R. Lyons. 2003. "Customer trades and extreme events in foreign exchange." In P. Mizen (Ed.), Monetary History, Exchange Rates and Financial Markets: Essays in Honor of Charles Goodhart, Edward Elgar, Northampton, MA, 160-179.

Fleming, M. 1997. "The round-the-clock market for U.S. Treasury securities." Federal Reserve Bank of New York Economic Policy Review 3, 9-32.

Froot K. and T. Ramadorai. 2002. "Currency returns, institutional investor flows, and exchange rate fundamentals." NBER Working Paper 9080. 
Glosten, L. and P. Milgrom. 1985. "Bid, ask, and transaction prices in a specialist market with heterogeneously informed agents." Journal of Financial Economics 14, 71-100.

Grossman, S., and J. Stiglitz. 1980. "On the impossibility of informationally efficient markets." American Economic Review 70, 393-408.

Grammig, J., M. Melvin, and C. Schlag. 2005. "International cross-listed stock prices during overlapping trading hours: Price discovery and exchange rate effects." Journal of Empirical Finance 12, 139-164.

Guillaume, D., M. Dacorogna, R. Dave, U. Muller, R. Olsen, O. Pictet. 1995. "From the bird's eye to the microscope: A survey of new stylized facts of the intraday foreign exchange market." Finance and Stochastics 1, 95-129.

Hamilton, J. 1994. Time Series Analysis. Princeton University Press.

Hasbrouck, J. 1991a. "Measuring the information content of stock trades." Journal of Finance 46, 179-207.

Hasbrouck, J. 1991b. "The summary information content of stock trades: An Econometric Investigation." Review of Financial Studies 4, 571-91.

Hau, H. 2001. "Geographic patterns of trading profitability in Xetra." Economic Economic Review 45, 757-769.

Hau, H. 2005. "Location matters: An examination of trading profits." Journal of Finance forthcoming.

Judge, G., R. Carter, W. Griffiths, H. Lutkepohl, and T. Lee. 1988. Introduction to the Theory and Practice of Econometrics. New York, NY: John Wiley and Sons.

Kyle, P. 1985. "Continuous auctions and insider trading." Econometrica 53, 1315-1335.

Lyons, R. 1995. "Tests of microstructural hypotheses in the foreign exchange market." Journal of Financial Economics 39, 321-351.

Lyons, R. 1997. "A simultaneous trade model of the foreign exchange hot potato." Journal of International Economics 42, 275-98.

Mark, N. 1995. "Exchange rates and fundamentals: Evidence on long-horizon predictability." American Economic Review 85, 201-218. 
Meese, R. and K. Rogoff. 1983. "Empirical exchange rate models of the seventies: Do they fit out of sample? Journal of International Economics 14, 3-24.

Melvin, M. and B. Peiers Melvin. 2003. "The global transmission of volatility in the foreign exchange market." Review of Economics and Statistics 85, 670-679.

Mende, A., L. Menkhoff and C. Osler. 2006. "Price discovery in currency markets." Brandeis University working paper.

Naik N. and P. Yadev. 2003. "Risk management with derivatives by dealers and market quality in government bond markets." Journal of Finance 58, 1873-1904.

Neumark, D., P. Tinsley and S. Tosini.1991. "After-hours stock prices and post-crash hangovers." Journal of Finance 46, 159-178.

O’Hara, M. 1995. Market Microstructure Theory. Blackwell Publishers. Cambridge Massachusetts.

Osler, C. 2003. "Currency orders and exchange-rate dynamics: An explanation for the predictive success of technical analysis." Journal of Finance 58, 1791-1819.

Payne. R. 2003. "Informed trade in spot foreign exchange markets: An empirical investigation." Journal of International Economics 61, 307-329.

Psiers, B. 1997. "Informed traders, intervention, and price leadership: A Deeper View of the Microstructure of the Foreign Exchange Market." Journal of Finance 52, 1589-1614.

Rime, D. 2003. "New electronic trading systems in foreign exchange markets." Chapter 21 in New Economy Handbook. Elsevier Science.

Sapp, S. 2002. "Price leadership in the spot foreign exchange market." Journal of Financial and Quantitative Analysis 37, 425-448.

Stock, J. and M. Watson. 1988. "Testing for common trends." Journal of the American Statistical Association 83, 1097-1107. 
Table 1: Daily Summary Statistics for Exchange Rate Quotes and Initiated Trades

Returns are defined as the log difference in the exchange rate between the beginning and the end of each 24-hour period (multiplied by 100). The exchange rate is the midpoint between the best bid and offer quotes at the end of each period. Volatility is the realized volatility, which is calculated as the sum of all intraday 5-minute squared returns in each 24-hour period. Volume and gross trades are the sum of trade amounts and the number of trades across the day. The fifthorder Ljung-Box Q-test statistic for autocorrelation is distributed $\chi^{2}(5)$ with an asymptotic critical value (5\% level) of 11.07. Sample: October 1, 2000-September 30, 2002, number of daily observations: 448 .

\begin{tabular}{lrrrr}
\hline \multicolumn{1}{c}{ CAD } & Returns (\%) & Volatility (\%) & Volume (\$U.S., Mil.) & Gross Trades \\
Mean & & & & \\
Median & 0.016 & 0.176 & 1756.12 & 866.31 \\
Std. Deviation & 0.024 & 0.160 & 1747.00 & 850.00 \\
Skewness & 0.358 & 0.077 & 669.51 & 312.31 \\
Kurtosis & -0.011 & 1.816 & 0.71 & 0.82 \\
Autocorrelation & 2.723 & 8.331 & 4.62 & 5.67 \\
\multicolumn{1}{c}{ AUD } & 6.311 & 48.763 & 23.09 & 29.19 \\
Mean & & & & \\
Median & 0.002 & 0.717 & 1787.93 & 1038.12 \\
Std. Deviation & 0.000 & 0.645 & 1887.00 & 1109.50 \\
Skewness & 0.672 & 0.450 & 897.58 & 501.21 \\
Kurtosis & -0.696 & 2.719 & -0.27 & -0.47 \\
Autocorrelation & 5.999 & 20.082 & 2.78 & 2.88 \\
\multicolumn{1}{c}{ NZD } & 5.434 & 67.774 & 29.20 & 26.20 \\
Mean & & & & \\
Median & -0.045 & 1.765 & 314.19 & 205.37 \\
Std. Deviation & -0.035 & 1.566 & 303.00 & 200.50 \\
Skewness & 0.757 & 0.964 & 115.00 & 67.68 \\
Kurtosis & -0.172 & 1.167 & 0.58 & 0.39 \\
Autocorrelation & 3.428 & 4.221 & 3.70 & 3.59 \\
\hline
\end{tabular}


Table 2: Trades Initiated Across Locations and Across Regional Hours

Gross trades are the number of trades initiated in each location across the day or across regional business hours. Sample: October 1, 2000-September 30, 2002, number of daily observations: 448 .

\begin{tabular}{|c|c|c|c|c|c|c|c|}
\hline & & Australia & Canada & Japan & New Zealand & U.K. & U.S. \\
\hline \multicolumn{8}{|l|}{ CAD } \\
\hline Mean & & 28.33 & 347.23 & 20.51 & 0.06 & 145.97 & 276.64 \\
\hline Median & & 25.00 & 348.00 & 18.00 & 0.00 & 136.00 & 283.00 \\
\hline \multirow[t]{6}{*}{ Std. Dev. } & & 19.54 & 138.99 & 14.20 & 0.36 & 82.27 & 107.63 \\
\hline & Asia & 21.60 & 1.21 & 15.58 & 0.01 & 2.56 & 7.58 \\
\hline & Asia-Europe & 2.49 & 0.00 & 3.18 & 0.01 & 20.15 & 2.35 \\
\hline & Europe & 2.17 & 8.29 & 0.91 & 0.00 & 58.61 & 8.16 \\
\hline & Europe-N.A. & 0.20 & 219.06 & 0.65 & 0.00 & 61.86 & 158.72 \\
\hline & N.America & 1.96 & 118.73 & 1.25 & 0.05 & 3.09 & 99.59 \\
\hline \multicolumn{8}{|l|}{ AUD } \\
\hline Mean & & 297.80 & 19.30 & 32.78 & 7.75 & 313.50 & 200.16 \\
\hline Median & & 304.50 & 16.00 & 31.00 & 5.50 & 340.00 & 210.00 \\
\hline \multirow[t]{6}{*}{ Std. Dev. } & & 147.79 & 18.08 & 22.52 & 7.21 & 170.87 & 115.77 \\
\hline & Asia & 192.50 & 0.04 & 26.52 & 2.76 & 6.53 & 6.08 \\
\hline & Asia-Europe & 18.80 & 0.00 & 3.70 & 0.71 & 53.53 & 0.83 \\
\hline & Europe & 20.42 & 0.82 & 1.75 & 0.58 & 115.14 & 4.24 \\
\hline & Europe-N.A. & 30.21 & 11.87 & 0.40 & 0.09 & 130.90 & 115.31 \\
\hline & N.America & 36.26 & 6.63 & 0.34 & 3.52 & 7.28 & 73.60 \\
\hline \multicolumn{8}{|l|}{ NZD } \\
\hline Mean & & 20.07 & 2.72 & 1.73 & 46.47 & 80.51 & 32.87 \\
\hline Median & & 19.00 & 1.00 & 1.00 & 47.00 & 75.50 & 28.00 \\
\hline \multirow[t]{6}{*}{ Std. Dev. } & & 10.78 & 4.61 & 2.37 & 21.88 & 33.92 & 21.84 \\
\hline & Asia & 14.71 & 0.02 & 1.26 & 24.26 & 1.03 & 0.41 \\
\hline & Asia-Europe & 1.11 & 0.00 & 0.27 & 4.06 & 13.19 & 0.07 \\
\hline & Europe & 0.58 & 0.09 & 0.16 & 3.52 & 28.97 & 0.80 \\
\hline & Europe-N.A. & 1.18 & 1.65 & 0.00 & 5.42 & 35.51 & 21.62 \\
\hline & N.America & 2.53 & 0.97 & 0.04 & 9.22 & 1.84 & 9.85 \\
\hline
\end{tabular}


Table 3: Regional Business Hours, GMT Time

\begin{tabular}{lcc}
\hline Trading Region (duration): & No Daylight Savings & With Daylight Savings \\
\hline & & \\
Asia (9.5 hours) & $22: 00-07: 30$ & $21: 00-06: 30$ \\
Asia-Europe (1.5 hours) & $07: 30-09: 00$ & $06: 30-08: 00$ \\
Europe (3.5 hours) & $09: 00-12: 30$ & $08: 00-11: 30$ \\
Europe-N. America (4.5 hours) & $12: 30-17: 00$ & $11: 30-16: 00$ \\
North America (5 hours) & $17: 00-22: 00$ & $16: 00-21: 00$ \\
\hline
\end{tabular}


Table 4: Exchange Rate Efficiency Across Regional Time Zones, CAD

Regression estimates of overnight CAD exchange rate changes in each regional time zone to movements in the exchange rate in each regional time zones over the previous business day. Reported standard errors (in parentheses) are corrected for heteroskedasticity. Sample: October 1, 2000-September 30, 2002, number of daily observations: 448.

\begin{tabular}{|c|c|c|c|c|c|c|}
\hline \multirow{2}{*}{$\begin{array}{c}\text { Overnight } \\
\text { Response in: }\end{array}$} & & \multicolumn{5}{|c|}{ Exchange Rate Movements at the Close of Business Hours in: } \\
\hline & & Asia & Asia-Europe & Europe & Europe-N. A. & N. America \\
\hline \multirow[t]{4}{*}{ Asia } & $\widehat{\beta}$ & & 0.828 & 0.971 & 1.084 & 1.010 \\
\hline & & & $(0.202)$ & $(0.089)$ & $(0.029)$ & $(0.011)$ \\
\hline & Adj. $R^{2}$ & & 0.034 & 0.209 & 0.754 & 0.944 \\
\hline & D-W Stat. & & 2.064 & 2.162 & 2.045 & 2.015 \\
\hline \multirow[t]{4}{*}{ Asia-Europe } & $\widehat{\beta}$ & 0.999 & & 1.061 & 1.110 & 1.010 \\
\hline & & $(0.003)$ & & $(0.105)$ & $(0.034)$ & $(0.019)$ \\
\hline & Adj. $R^{2}$ & 0.995 & & 0.183 & 0.701 & 0.859 \\
\hline & D-W Stat. & 2.089 & & 2.123 & 2.081 & 2.002 \\
\hline \multirow[t]{4}{*}{ Europe } & $\widehat{\beta}$ & 0.995 & 0.991 & & 1.083 & 0.997 \\
\hline & & $(0.012)$ & $(0.003)$ & & $(0.042)$ & $(0.024)$ \\
\hline & Adj. $R^{2}$ & 0.933 & 0.993 & & 0.589 & 0.790 \\
\hline & D-W Stat. & 1.980 & 1.991 & & 2.084 & 2.027 \\
\hline \multirow[t]{4}{*}{ Europe-N. A. } & $\widehat{\beta}$ & 1.028 & 1.008 & 0.998 & & 1.080 \\
\hline & & $(0.040)$ & $(0.033)$ & $(0.007)$ & & $(0.063)$ \\
\hline & Adj. $R^{2}$ & 0.587 & 0.669 & 0.976 & & 0.389 \\
\hline & D-W Stat. & 1.845 & 1.855 & 2.046 & & 1.792 \\
\hline \multirow[t]{4}{*}{ N. America } & $\widehat{\beta}$ & 0.859 & 0.884 & 0.923 & 1.003 & \\
\hline & & $(0.100)$ & $(0.085)$ & $(0.056)$ & $(0.004)$ & \\
\hline & Adj. $R^{2}$ & 0.139 & 0.190 & 0.375 & 0.989 & \\
\hline & D-W Stat. & 1.941 & 1.977 & 2.027 & 1.838 & \\
\hline
\end{tabular}


Table 5: Exchange Rate Efficiency Across Regional Time Zones, AUD

Regression estimates of AUD overnight exchange rate changes in each regional time zone to movements in the exchange rate in each regional time zones over the previous business day. Reported standard errors (in parentheses) are corrected for heteroskedasticity. Sample: October 1, 2000-September 30, 2002, number of daily observations: 448.

\begin{tabular}{|c|c|c|c|c|c|c|}
\hline \multirow{2}{*}{$\begin{array}{c}\text { Overnight } \\
\text { Response in: }\end{array}$} & & \multicolumn{5}{|c|}{ Exchange Rate Movements at the Close of Business Hours in: } \\
\hline & & Asia & Asia-Europe & Europe & Europe-N. A. & N. America \\
\hline \multirow[t]{4}{*}{ Asia } & $\widehat{\beta}$ & & 0.830 & 1.018 & 1.017 & 0.983 \\
\hline & & & $(0.157)$ & $(0.075)$ & $(0.037)$ & $(0.022)$ \\
\hline & Adj. $R^{2}$ & & 0.056 & 0.290 & 0.621 & 0.808 \\
\hline & D-W Stat. & & 2.198 & 2.126 & 2.069 & 1.992 \\
\hline \multirow[t]{4}{*}{ Asia-Europe } & $\widehat{\beta}$ & 0.999 & & 1.164 & 1.062 & 0.954 \\
\hline & & $(0.003)$ & & $(0.095)$ & $(0.047)$ & $(0.035)$ \\
\hline & Adj. $R^{2}$ & 0.994 & & 0.248 & 0.524 & 0.613 \\
\hline & D-W Stat. & 1.917 & & 2.132 & 2.005 & 1.902 \\
\hline \multirow[t]{4}{*}{ Europe } & $\widehat{\beta}$ & 1.034 & 1.001 & & 0.992 & 0.922 \\
\hline & & $(0.015)$ & $(0.004)$ & & $(0.066)$ & $(0.048)$ \\
\hline & Adj. $R^{2}$ & 0.910 & 0.991 & & 0.328 & 0.443 \\
\hline & D-W Stat. & 1.961 & 2.128 & & 1.872 & 1.755 \\
\hline \multirow[t]{4}{*}{ Europe-N. A. } & $\widehat{\beta}$ & 1.050 & 0.992 & 0.995 & & 0.758 \\
\hline & & $(0.033)$ & $(0.027)$ & $(0.004)$ & & (0.099) \\
\hline & Adj. $R^{2}$ & 0.681 & 0.747 & 0.990 & & 0.112 \\
\hline & D-W Stat. & 1.955 & 2.121 & 1.925 & & 1.770 \\
\hline \multirow[t]{4}{*}{ N. America } & $\widehat{\beta}$ & 1.071 & 0.988 & 0.974 & 0.999 & \\
\hline & & $(0.054)$ & $(0.046)$ & $(0.031)$ & $(0.003)$ & \\
\hline & Adj. $R^{2}$ & 0.461 & 0.501 & 0.685 & 0.994 & \\
\hline & D-W Stat. & 1.948 & 2.043 & 1.908 & 2.011 & \\
\hline
\end{tabular}


Table 6: Exchange Rate Efficiency Across Regional Time Zones, NZD

Regression estimates of overnight NZD exchange rate changes in each regional time zone to movements in the exchange rate in each regional time zones over the previous business day. Reported standard errors (in parentheses) are corrected for heteroskedasticity. Sample: October 1, 2000-September 30, 2002, number of daily observations: 448.

\begin{tabular}{|c|c|c|c|c|c|c|}
\hline \multirow{2}{*}{$\begin{array}{c}\text { Overnight } \\
\text { Response in: }\end{array}$} & & \multicolumn{5}{|c|}{ Exchange Rate Movements at the Close of Business Hours in: } \\
\hline & & Asia & Asia-Europe & Europe & Europe-N. A. & N. America \\
\hline \multirow[t]{4}{*}{ Asia } & $\widehat{\beta}$ & & 0.735 & 0.821 & 0.859 & 0.919 \\
\hline & & & $(0.128)$ & $(0.070)$ & $(0.041)$ & $(0.027)$ \\
\hline & Adj. $R^{2}$ & & 0.065 & 0.229 & 0.491 & 0.714 \\
\hline & D-W Stat. & & 2.204 & 2.194 & 2.110 & 2.026 \\
\hline \multirow[t]{4}{*}{ Asia-Europe } & $\widehat{\beta}$ & 0.992 & & 1.047 & 0.937 & 0.948 \\
\hline & & $(0.004)$ & & $(0.102)$ & $(0.053)$ & $(0.040)$ \\
\hline & Adj. $R^{2}$ & 0.989 & & 0.188 & 0.406 & 0.553 \\
\hline & D-W Stat. & 1.945 & & 2.082 & 1.931 & 1.800 \\
\hline \multirow[t]{4}{*}{ Europe } & $\widehat{\beta}$ & 1.016 & 1.009 & & 0.808 & 0.863 \\
\hline & & $(0.017)$ & $(0.004)$ & & $(0.065)$ & $(0.050)$ \\
\hline & Adj. $R^{2}$ & 0.880 & 0.990 & & 0.253 & 0.392 \\
\hline & D-W Stat. & 1.949 & 2.100 & & 1.904 & 1.785 \\
\hline \multirow[t]{4}{*}{ Europe-N. A. } & $\widehat{\beta}$ & 1.034 & 1.024 & 1.003 & & 0.847 \\
\hline & & $(0.032)$ & $(0.024)$ & $(0.005)$ & & $(0.089)$ \\
\hline & Adj. $R^{2}$ & 0.694 & 0.798 & 0.988 & & 0.166 \\
\hline & D-W Stat. & 1.871 & 1.874 & 1.904 & & 1.731 \\
\hline \multirow[t]{4}{*}{ N. America } & $\widehat{\beta}$ & 0.939 & 0.942 & 0.886 & 0.993 & \\
\hline & & $(0.042)$ & $(0.032)$ & $(0.032)$ & $(0.005)$ & \\
\hline & Adj. $R^{2}$ & 0.516 & 0.556 & 0.622 & 0.986 & \\
\hline & D-W Stat. & 2.046 & 2.100 & 1.958 & 1.897 & \\
\hline
\end{tabular}


Table 7: Impulse Response Functions and Variance Decompositions of Returns

Impulse responses and variance decompositions of CAD (Panel A), AUD (Panel $\mathrm{B}$ ), and NZD (Panel C) exchange rate returns based on vector autoregression estimates. Models include exchange rate returns and a set of geographic location order flow variables, and are estimated for each currency market across each set of regional business hours. The lowest long-run impulse response and variance decomposition of exchange rate returns across all possible orderings of variables are presented. The Schwartz Information Criterion is used to determine lag length. If impulse response or variance decomposition statistics are not statistically significant at the $5 \%$ level the entry is left blank. Standard errors were estimated using a residual-based bootstrap of the VAR model with 1000 bootstrap replications. Sample: October 1, 2000-September 30, 2002, 5-minutes frequency.

\begin{tabular}{|c|c|c|c|c|c|c|}
\hline Panel A: CAD returns & Australia & Canada & Japan & New Zealand & U.K. & U.S. \\
\hline \multicolumn{7}{|c|}{ Cumulative response of exchange rate returns to trade innovations in each location (\%) } \\
\hline Asia & 0.441 & & 0.362 & & & 0.167 \\
\hline Asia-Europe & 0.277 & & 0.323 & & 0.682 & \\
\hline Europe & & 0.405 & & & 0.754 & 0.360 \\
\hline Europe-N.A. & & 0.590 & & & 0.110 & 0.514 \\
\hline N. America & & 0.659 & & & & 0.411 \\
\hline \multicolumn{7}{|c|}{ Variance decomposition of the 20 -step ahead forecast variance of cumulative returns (\%) } \\
\hline Asia & 0.100 & & 0.067 & & & 0.014 \\
\hline Asia-Europe & 0.071 & & 0.098 & & 0.428 & \\
\hline Europe & & 0.132 & & & 0.458 & 0.108 \\
\hline Europe-N.A. & & 0.338 & & & 0.120 & 0.269 \\
\hline N. America & & 0.485 & & & & 0.201 \\
\hline
\end{tabular}




\begin{tabular}{|c|c|c|c|c|c|c|}
\hline Panel B: AUD returns & Australia & Canada & Japan & New Zealand & U.K. & U.S. \\
\hline \multicolumn{7}{|c|}{ Cumulative response of exchange rate returns to trade innovations in each location (\%) } \\
\hline Asia & 1.185 & & 0.304 & & 0.152 & 0.362 \\
\hline Asia-Europe & 0.661 & & 0.262 & & 0.907 & 0.158 \\
\hline Europe & 0.483 & & 0.106 & & 1.048 & 0.168 \\
\hline Europe-N.A. & 0.340 & & & & 0.730 & 0.647 \\
\hline N. America & 0.668 & 0.472 & & & 0.412 & 0.960 \\
\hline \multicolumn{7}{|c|}{ Variance decomposition of the 20 -step ahead forecast variance of cumulative returns (\%) } \\
\hline Asia & 0.459 & & 0.032 & & 0.008 & 0.043 \\
\hline Asia-Europe & 0.222 & & 0.036 & & 0.402 & 0.032 \\
\hline Europe & 0.127 & & 0.006 & & 0.547 & 0.014 \\
\hline Europe-N.A. & 0.073 & & & & 0.314 & 0.253 \\
\hline N. America & 0.113 & 0.057 & & & 0.043 & 0.235 \\
\hline Panel C: NZD returns & Australia & Canada & Japan & New Zealand & U.K. & U.S. \\
\hline \multicolumn{7}{|c|}{ Cumulative response of exchange rate returns to trade innovations in each location (\%) } \\
\hline Asia & 1.466 & & & 2.241 & & \\
\hline Asia-Europe & & & & 1.591 & 2.074 & \\
\hline Europe & & & & 0.732 & 2.710 & \\
\hline Europe-N.A. & & & & & 2.203 & 2.385 \\
\hline N. America & & & & 2.121 & & 2.310 \\
\hline \multicolumn{7}{|c|}{ Variance decomposition of the 20 -step ahead forecast variance of cumulative returns (\%) } \\
\hline Asia & 0.033 & & & 0.076 & & \\
\hline Asia-Europe & & & & 0.137 & 0.229 & \\
\hline Europe & & & & 0.029 & 0.383 & \\
\hline Europe-N.A. & & & & & 0.273 & 0.168 \\
\hline N. America & & & & 0.062 & & 0.073 \\
\hline
\end{tabular}


Table 8: Impulse Response Functions and Variance Decompositions, High Volatility Days

Impulse responses and variance decompositions of CAD (Panel A), AUD (Panel B), and NZD (Panel C) exchange rate returns based on vector autoregression estimates. Models include exchange rate returns and a set of geographic location order flow variables, and are estimated for each currency market across each set of regional business hours. The top 25\% most volatile days (based on realized volatility) are chosen in each regional time zone. The lowest long-run impulse response and variance decomposition of exchange rate returns across all possible orderings of variables are presented. The Schwartz Information Criterion is used to determine lag length. If impulse response or variance decomposition statistics are not statistically significant at the $5 \%$ level the entry is left blank. Standard errors were estimated using a residual-based bootstrap of the VAR model with 1000 bootstrap replications. Sample: October 1, 2000-September 30, 2002, 5minutes frequency.

\begin{tabular}{|c|c|c|c|c|c|c|}
\hline Panel A: CAD returns & Australia & Canada & Japan & New Zealand & U.K. & U.S. \\
\hline \multicolumn{7}{|c|}{ Cumulative response of exchange rate returns to trade innovations in each location (\%) } \\
\hline Asia & 0.601 & & 0.433 & & & 0.314 \\
\hline Asia-Europe & 0.207 & & 0.343 & & 0.823 & \\
\hline Europe & & 0.490 & & & 1.062 & 0.479 \\
\hline Europe-N.A. & & 0.756 & & & 0.101 & 0.407 \\
\hline N. America & & 0.767 & & & & 0.331 \\
\hline \multicolumn{7}{|c|}{ Variance decomposition of the 20 -step ahead forecast variance of cumulative returns (\%) } \\
\hline Asia & 0.139 & & 0.071 & & & 0.037 \\
\hline Asia-Europe & 0.040 & & 0.111 & & 0.621 & \\
\hline Europe & & 0.104 & & & 0.496 & 0.105 \\
\hline Europe-N.A. & & 0.447 & & & 0.010 & 0.142 \\
\hline N. America & & 0.611 & & & & 0.129 \\
\hline
\end{tabular}




\begin{tabular}{|c|c|c|c|c|c|c|}
\hline Panel B: AUD returns & Australia & Canada & Japan & New Zealand & U.K. & U.S. \\
\hline \multicolumn{7}{|c|}{ Cumulative response of exchange rate returns to trade innovations in each location (\%) } \\
\hline Asia & 1.403 & & 0.087 & & 0.120 & 0.257 \\
\hline Asia-Europe & 0.733 & & 0.955 & & 1.005 & 0.777 \\
\hline Europe & 0.183 & & 0.326 & & 1.627 & \\
\hline Europe-N.A. & 0.480 & 0.141 & & & 0.715 & 0.983 \\
\hline N. America & 1.168 & 1.042 & & & 0.511 & 1.253 \\
\hline \multicolumn{7}{|c|}{ Variance decomposition of the 20 -step ahead forecast variance of cumulative returns (\%) } \\
\hline Asia & 0.512 & & 0.034 & & 0.015 & 0.017 \\
\hline Asia-Europe & 0.135 & & 0.218 & & 0.237 & 0.137 \\
\hline Europe & 0.012 & & 0.031 & & 0.751 & \\
\hline Europe-N.A. & 0.085 & 0.058 & & & 0.197 & 0.337 \\
\hline N. America & 0.154 & 0.121 & & & & 0.184 \\
\hline Panel C: NZD returns & Australia & Canada & Japan & New Zealand & U.K. & U.S. \\
\hline \multicolumn{7}{|c|}{ Cumulative response of exchange rate returns to trade innovations in each location (\%) } \\
\hline Asia & 1.882 & & & 2.442 & & \\
\hline Asia-Europe & & & & 2.487 & 2.127 & \\
\hline Europe & & & & 1.028 & 3.447 & \\
\hline Europe-N.A. & & & & & 2.097 & 2.175 \\
\hline N. America & & & & 2.821 & & 2.561 \\
\hline \multicolumn{7}{|c|}{ Variance decomposition of the 20 -step ahead forecast variance of cumulative returns (\%) } \\
\hline Asia & 0.030 & & & 0.051 & & \\
\hline Asia-Europe & & & & 0.327 & 0.234 & \\
\hline Europe & & & & 0.037 & 0.407 & \\
\hline Europe-N.A. & & & & & 0.230 & 0.245 \\
\hline N. America & & & & 0.061 & & 0.050 \\
\hline
\end{tabular}


Table 9: Impulse Response Functions and Variance Decompositions, Low Volume Days

Impulse responses and variance decompositions of CAD (Panel A), AUD (Panel B), and NZD (Panel C) exchange rate returns based on vector autoregression estimates. Models include exchange rate returns and a set of geographic location order flow variables, and are estimated for each currency market across each set of regional business hours. The $25 \%$ least active days (based on trading volumes) are chosen in each regional time zone. The lowest long-run impulse response and variance decomposition of exchange rate returns across all possible orderings of variables are presented. The Schwartz Information Criterion is used to determine lag length. If impulse response or variance decomposition statistics are not statistically significant at the $5 \%$ level the entry is left blank. Standard errors were estimated using a residual-based bootstrap of the VAR model with 1000 bootstrap replications. Sample: October 1, 2000-September 30, 2002, 5minutes frequency.

\begin{tabular}{|c|c|c|c|c|c|c|}
\hline Panel A: CAD returns & Australia & Canada & Japan & New Zealand & U.K. & U.S. \\
\hline \multicolumn{7}{|c|}{ Cumulative response of exchange rate returns to trade innovations in each location (\%) } \\
\hline Asia & 0.241 & & 0.217 & & & 0.098 \\
\hline Asia-Europe & 0.482 & & 0.193 & & 0.562 & \\
\hline Europe & & 0.324 & & & 0.621 & 0.297 \\
\hline Europe-N.A. & & 0.754 & & & 0.172 & 0.606 \\
\hline N. America & & 0.571 & & & & 0.372 \\
\hline \multicolumn{7}{|c|}{ Variance decomposition of the 20 -step ahead forecast variance of cumulative returns (\%) } \\
\hline Asia & 0.026 & & 0.021 & & & 0.040 \\
\hline Asia-Europe & 0.190 & & 0.032 & & 0.261 & \\
\hline Europe & & 0.070 & & & 0.247 & 0.057 \\
\hline Europe-N.A. & & 0.417 & & & 0.024 & 0.283 \\
\hline N. America & & 0.322 & & & & 0.141 \\
\hline
\end{tabular}




\begin{tabular}{|c|c|c|c|c|c|c|}
\hline Panel B: AUD returns & Australia & Canada & Japan & New Zealand & U.K. & U.S. \\
\hline \multicolumn{7}{|c|}{ Cumulative response of exchange rate returns to trade innovations in each location (\%) } \\
\hline Asia & 1.260 & & 0.347 & & 0.225 & 0.308 \\
\hline Asia-Europe & 0.561 & & 0.050 & & 1.551 & 0.086 \\
\hline Europe & 0.541 & & & & 1.413 & \\
\hline Europe-N.A. & 0.463 & & & & 1.359 & 0.442 \\
\hline N. America & 0.862 & 0.150 & & & & 0.785 \\
\hline \multicolumn{7}{|c|}{ Variance decomposition of the 20 -step ahead forecast variance of cumulative returns (\%) } \\
\hline Asia & 0.280 & & 0.021 & & 0.012 & 0.017 \\
\hline Asia-Europe & 0.064 & & 0.010 & & 0.455 & 0.001 \\
\hline Europe & 0.054 & & & & 0.369 & \\
\hline Europe-N.A. & 0.057 & & & & 0.473 & 0.053 \\
\hline N. America & 0.091 & 0.008 & & & & 0.076 \\
\hline Panel C: NZD returns & Australia & Canada & Japan & New Zealand & U.K. & U.S. \\
\hline \multicolumn{7}{|c|}{ Cumulative response of exchange rate returns to trade innovations in each location (\%) } \\
\hline Asia & 0.814 & & & 2.057 & & \\
\hline Asia-Europe & & & & 1.919 & 2.159 & \\
\hline Europe & & & & 1.171 & 1.662 & \\
\hline Europe-N.A. & & & & & 2.016 & 1.302 \\
\hline N. America & & & & 1.330 & & 1.646 \\
\hline \multicolumn{7}{|c|}{ Variance decomposition of the 20 -step ahead forecast variance of cumulative returns (\%) } \\
\hline Asia & 0.013 & & & 0.083 & & \\
\hline Asia-Europe & & & & 0.134 & 0.166 & \\
\hline Europe & & & & 0.062 & 0.126 & \\
\hline Europe-N.A. & & & & & 0.139 & 0.058 \\
\hline N. America & & & & 0.027 & & 0.042 \\
\hline
\end{tabular}


Table 10: Exchange Rate Return and Order Flow Correlations Across Markets

The table reports correlation coefficient estimates of exchange rate returns and market-wide order flow across regional time zones in CAD, AUD and NZD markets. A ' $*$ ' denotes significance at the 5\% level. Sample: October 1, 2000September 30, 2002, number of daily observations: 448.

\begin{tabular}{lrrrrrrrr}
\hline Correlation Coefficients & \multicolumn{3}{c}{ Returns } & & \multicolumn{3}{c}{ Order Flow } \\
\cline { 3 - 4 } \cline { 7 - 8 } Region: & & CAD & AUD & NZD & & CAD & AUD & NZD \\
\hline Asia & & & & & & & & \\
& CAD & 1.00 & & & & 1.00 & & \\
& AUD & 0.02 & 1.00 & & & -0.03 & 1.00 & \\
& NZD & 0.00 & $* 0.74$ & 1.00 & & -0.05 & $* 0.26$ & 1.00
\end{tabular}

Asia-Europe

$\begin{array}{rrrrrrr}\text { CAD } & 1.00 & & & 1.00 & & \\ \text { AUD } & * 0.19 & 1.00 & & -0.05 & 1.00 & \\ \text { NZD } & * 0.16 & * 0.69 & 1.00 & -0.01 & * 0.07 & 1.00\end{array}$

Europe

$\begin{array}{rrrrrrr}\text { CAD } & 1.00 & & & 1.00 & & \\ \text { AUD } & * 0.18 & 1.00 & & -0.05 & 1.00 & \\ \text { NZD } & * 0.19 & * 0.74 & 1.00 & -0.01 & * 0.10 & 1.00\end{array}$

Europe-N. A.

$\begin{array}{rrrrrrr}\text { CAD } & 1.00 & & & 1.00 & & \\ \text { AUD } & * 0.24 & 1.00 & & -0.07 & 1.00 & \\ \text { NZD } & * 0.21 & * 0.72 & 1.00 & 0.01 & * 0.21 & 1.00\end{array}$

N. America

\begin{tabular}{rrrrrrr} 
CAD & 1.00 & & & 1.00 & & \\
AUD & $* 0.17$ & 1.00 & & 0.01 & 1.00 & \\
NZD & $* 0.13$ & $* 0.71$ & 1.00 & -0.07 & $* 0.14$ & 1.00 \\
\hline
\end{tabular}


Table 11: Exchange Rate Changes from Cross Market Order Flow, CAD

The table reports regression estimates $(\times 100,000)$ of exchange rate changes across regional time zones from contemporaneous order flow in CAD, AUD and NZD markets. Reported standard errors (in parentheses) are corrected for heteroskedasticity. Sample: October 1, 2000-September 30, 2002, number of daily observations: 448 .

\begin{tabular}{|c|c|c|c|c|}
\hline \multirow{2}{*}{$\begin{array}{l}\text { CAD Returns } \\
\text { Region: }\end{array}$} & \multicolumn{4}{|c|}{ Order Flow in: } \\
\hline & $\mathrm{CAD}$ & AUD & NZD & Adj. $R^{2}$ \\
\hline \multirow[t]{4}{*}{ Asia } & 1.190 & & & 0.031 \\
\hline & $(0.499)$ & & & \\
\hline & 1.249 & 0.034 & 1.089 & 0.053 \\
\hline & $(0.498)$ & $(0.145)$ & $(0.476)$ & \\
\hline \multirow[t]{4}{*}{ Asia-Europe } & 0.205 & & & 0.004 \\
\hline & $(0.309$ & & & \\
\hline & 0.225 & 0.192 & 0.328 & 0.005 \\
\hline & $(0.309)$ & $(0.168)$ & $(0.482)$ & \\
\hline \multirow[t]{4}{*}{ Europe } & 0.540 & & & 0.019 \\
\hline & $(0.274)$ & & & \\
\hline & 0.515 & 0.440 & 0.045 & 0.031 \\
\hline & $(0.274)$ & $(0.226)$ & $(0.659)$ & \\
\hline \multirow[t]{4}{*}{ Europe-N. A. } & 0.131 & & & 0.014 \\
\hline & $(0.202)$ & & & \\
\hline & 0.120 & 0.149 & 0.712 & 0.019 \\
\hline & $(0.202)$ & $(0.209)$ & $(0.724)$ & \\
\hline \multirow[t]{4}{*}{ N. America } & 0.181 & & & 0.013 \\
\hline & $(0.236)$ & & & \\
\hline & 0.149 & 0.249 & 1.926 & 0.021 \\
\hline & $(0.236)$ & $(0.294)$ & $(0.937)$ & \\
\hline
\end{tabular}


Table 12: Exchange Rate Changes from Cross Market Order Flow, AUD

The table reports regression estimates $(\times 100,000)$ of exchange rate changes across regional time zones from contemporaneous order flow in CAD, AUD and NZD markets. Reported standard errors (in parentheses) are corrected for heteroskedasticity. Sample: October 1, 2000-September 30, 2002, number of daily observations: 448 .

\begin{tabular}{|c|c|c|c|c|}
\hline \multirow{2}{*}{$\begin{array}{l}\text { AUD Returns } \\
\text { Region: }\end{array}$} & \multicolumn{4}{|c|}{ Order Flow in: } \\
\hline & $\mathrm{CAD}$ & AUD & NZD & Adj. $R^{2}$ \\
\hline \multirow[t]{4}{*}{ Asia } & & 0.716 & & 0.011 \\
\hline & & $(0.436)$ & & \\
\hline & 3.624 & 0.879 & 2.518 & 0.051 \\
\hline & $(1.544)$ & $(0.449)$ & $(1.475)$ & \\
\hline \multirow[t]{4}{*}{ Asia-Europe } & & 1.581 & & 0.106 \\
\hline & & $(0.379)$ & & \\
\hline & 1.549 & 1.665 & 4.894 & 0.254 \\
\hline & $(0.682)$ & $(0.370)$ & $(1.062)$ & \\
\hline \multirow[t]{4}{*}{ Europe } & & 1.173 & & 0.040 \\
\hline & & $(0.442)$ & & \\
\hline & 1.206 & 1.228 & 3.041 & 0.096 \\
\hline & $(0.535)$ & $(0.440)$ & $(1.285)$ & \\
\hline \multirow[t]{4}{*}{ Europe-N. A. } & & 1.839 & & 0.211 \\
\hline & & $(0.311)$ & & \\
\hline & 0.148 & 1.875 & 0.749 & 0.203 \\
\hline & $(0.309)$ & $(0.320)$ & $(1.106)$ & \\
\hline \multirow[t]{4}{*}{ N. America } & & 0.606 & & 0.003 \\
\hline & & $(0.512)$ & & \\
\hline & 0.154 & 0.368 & 5.534 & 0.065 \\
\hline & $(0.410)$ & $(0.512)$ & $(1.630)$ & \\
\hline
\end{tabular}


Table 13: Exchange Rate Changes from Cross Market Order Flow, NZD

The table reports regression estimates $(\times 100,000)$ of exchange rate changes across regional time zones from contemporaneous order flow in CAD, AUD and NZD markets. Reported standard errors (in parentheses) are corrected for heteroskedasticity. Sample: October 1, 2000-September 30, 2002, number of daily observations: 448 .

\begin{tabular}{|c|c|c|c|c|}
\hline \multirow{2}{*}{$\begin{array}{l}\text { NZD Returns } \\
\text { Region: }\end{array}$} & \multicolumn{4}{|c|}{ Order Flow in: } \\
\hline & CAD & AUD & NZD & $\operatorname{Adj} . R^{2}$ \\
\hline \multirow[t]{4}{*}{ Asia } & & & 4.207 & 0.040 \\
\hline & & & $(1.580)$ & \\
\hline & 3.953 & 0.896 & 5.159 & 0.085 \\
\hline & $(1.700)$ & $(0.494)$ & $(1.624)$ & \\
\hline \multirow[t]{4}{*}{ Asia-Europe } & & & 4.573 & 0.080 \\
\hline & & & $(1.256)$ & \\
\hline & 1.370 & 1.383 & 4.893 & 0.154 \\
\hline & $(0.798)$ & $(0.434)$ & $(1.243)$ & \\
\hline \multirow[t]{4}{*}{ Europe } & & & 1.669 & 0.004 \\
\hline & & & $(1.296)$ & \\
\hline & 1.850 & 0.933 & 2.004 & 0.104 \\
\hline & $(0.533)$ & $(0.439)$ & $(1.281)$ & \\
\hline \multirow[t]{4}{*}{ Europe-N. A. } & & & 2.704 & 0.023 \\
\hline & & & $(1.273)$ & \\
\hline & 0.014 & 1.118 & 1.871 & 0.069 \\
\hline & $(0.362)$ & $(0.374)$ & $(1.294)$ & \\
\hline \multirow[t]{4}{*}{ N. America } & & & 6.517 & 0.066 \\
\hline & & & $(1.961)$ & \\
\hline & 0.670 & 0.141 & 6.641 & 0.065 \\
\hline & $(0.499)$ & $(0.623)$ & $(1.985)$ & \\
\hline
\end{tabular}


Table 14: Cross Market Effects, Impulse Response Functions and Variance Decompositions

Impulse responses and variance decompositions of CAD (Panel A), AUD (Panel $\mathrm{B}$ ), and NZD (Panel C) exchange rate returns based on vector autoregression estimates. Models include CAD, AUD and NZD exchange rate returns and a set of geographic location own market order flow variables, and are estimated for each currency market across each set of regional business hours. The lowest long-run impulse response and variance decomposition of exchange rate returns across all possible orderings of variables are presented. The Schwartz Information Criterion is used to determine lag length. If impulse response or variance decomposition statistics are not statistically significant at the $5 \%$ level the entry is left blank. Standard errors were estimated using a residual-based bootstrap of the VAR model with 1000 bootstrap replications. Sample: October 1, 2000-September 30, 2002, 5-minutes frequency.

\begin{tabular}{|c|c|c|c|c|c|}
\hline \multirow[t]{2}{*}{ Panel A: CAD returns } & \multicolumn{2}{|c|}{ Returns } & \multicolumn{3}{|c|}{ Order Flow } \\
\hline & AUD & NZD & CAD & AUD & NZD \\
\hline \multicolumn{6}{|c|}{ Cumulative response of exchange rate returns to innovations across markets (\%) } \\
\hline Asia & 0.110 & & 0.577 & & \\
\hline Asia-Europe & 0.187 & 0.124 & 0.827 & & \\
\hline Europe & 0.093 & & 0.988 & & \\
\hline Europe-N.A. & 0.241 & & 0.978 & & \\
\hline N. America & 0.128 & & 0.841 & & \\
\hline \multicolumn{6}{|c|}{ Variance decomposition of the 20 -step ahead forecast variance of cumulative returns (\%) } \\
\hline Asia & 0.006 & & 0.170 & & \\
\hline Asia-Europe & 0.030 & 0.014 & 0.611 & & \\
\hline Europe & 0.007 & & 0.813 & & \\
\hline Europe-N.A. & 0.051 & & 0.759 & & \\
\hline N. America & 0.019 & & 0.815 & & \\
\hline
\end{tabular}




\begin{tabular}{|c|c|c|c|c|c|}
\hline \multirow[t]{2}{*}{ Panel B: AUD returns } & \multicolumn{2}{|c|}{ Returns } & \multicolumn{3}{|c|}{ Order Flow } \\
\hline & $\mathrm{CAD}$ & NZD & $\mathrm{CAD}$ & AUD & NZD \\
\hline \multicolumn{6}{|c|}{ Cumulative response of exchange rate returns to innovations across markets (\%) } \\
\hline Asia & & 0.372 & & 1.442 & \\
\hline Asia-Europe & & 0.434 & 0.323 & 1.490 & \\
\hline Europe & 0.242 & 0.362 & & 1.434 & \\
\hline Europe-N.A. & 0.302 & 0.589 & & 1.457 & \\
\hline N. America & 0.329 & & & 1.530 & \\
\hline \multicolumn{6}{|c|}{ Variance decomposition of the 20-step ahead forecast variance of cumulative returns (\%) } \\
\hline Asia & & 0.033 & & 0.535 & \\
\hline Asia-Europe & & 0.049 & 0.029 & 0.644 & \\
\hline Europe & 0.018 & 0.039 & & 0.679 & \\
\hline Europe-N.A. & 0.025 & 0.089 & & 0.616 & \\
\hline N. America & 0.023 & & & 0.493 & \\
\hline
\end{tabular}

\begin{tabular}{lccccc}
\hline Panel C: NZD returns & \multicolumn{2}{c}{ Returns } & \multicolumn{3}{c}{ Order Flow } \\
\hline & CAD & AUD & CAD & AUD & NZD \\
\hline
\end{tabular}

Cumulative response of exchange rate returns to innovations across markets (\%)

$\begin{array}{lll}\text { Asia } & 1.318 & 2.782 \\ \text { Asia-Europe } & 1.863 & 3.077 \\ \text { Europe } & 1.606 & 2.957 \\ \text { Europe-N.A. } & 1.158 & 3.265 \\ \text { N. America } & 1.376 & 3.394\end{array}$

Variance decomposition of the 20-step ahead forecast variance of cumulative returns (\%)

$\begin{array}{lll}\text { Asia } & 0.021 & 0.097\end{array}$

$\begin{array}{lll}\text { Asia-Europe } & 0.086 & 0.238\end{array}$

$\begin{array}{lll}\text { Europe } & 0.071 & 0.247\end{array}$

$\begin{array}{lll}\text { Europe-N.A. } & 0.036 & 0.307\end{array}$

$\begin{array}{lll}\mathrm{N} . & \text { America } & 0.132\end{array}$ 
Figure 1: Daily CAD, AUD and NZD Exchange Rates (European Closing Hours)

Sample Period: October 1, 2000 to September 30, 2002

CAD

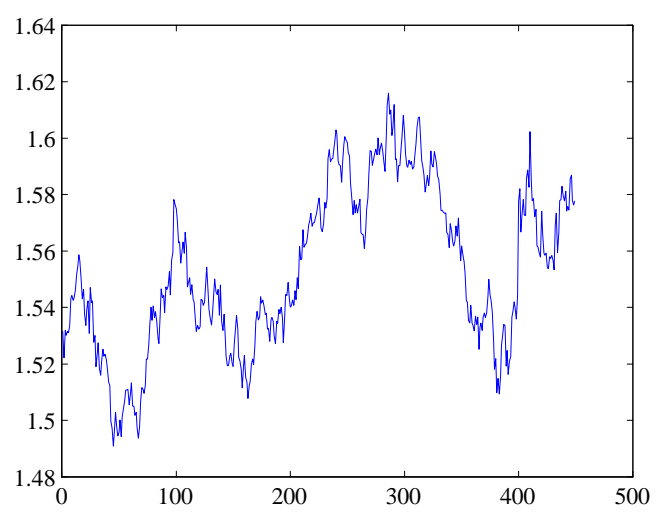

AUD

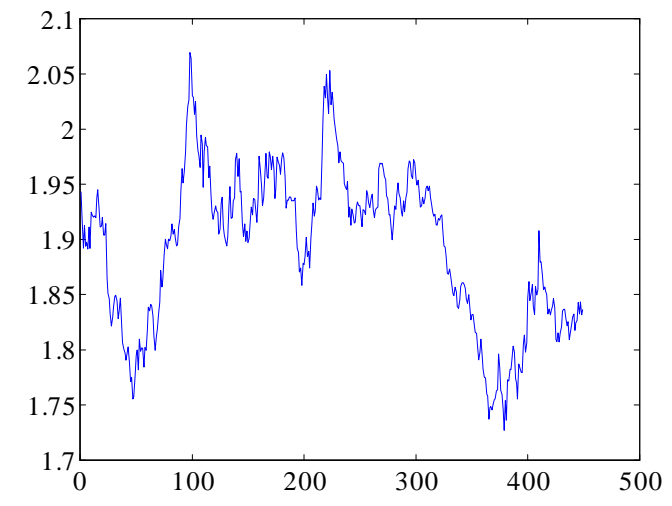

NZD

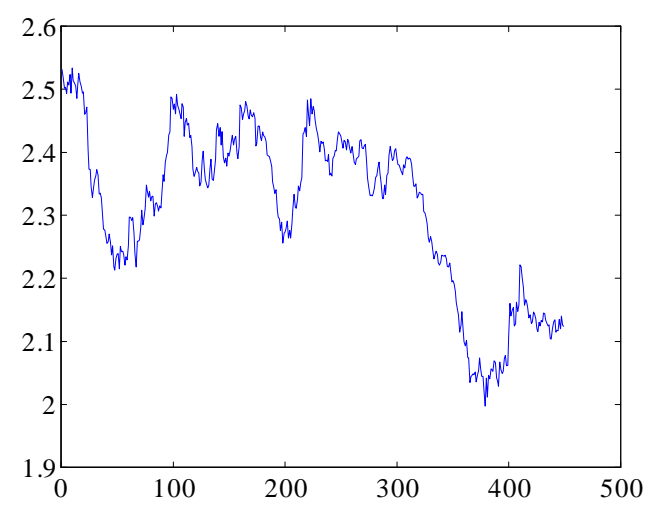


Figure 2: Gross Trades for CAD, AUD and NZD, hourly across 24-hour clock, GMT time CAD

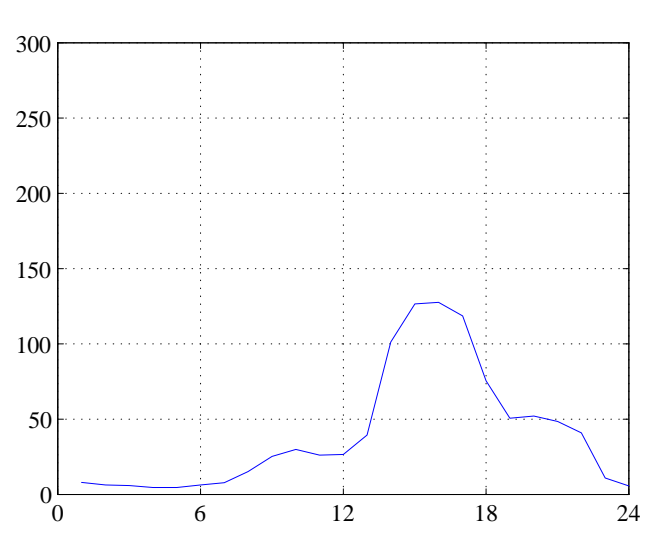

AUD

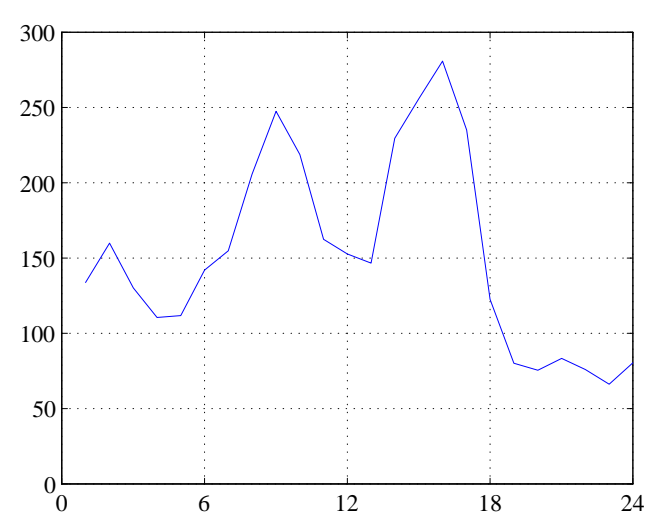

NZD

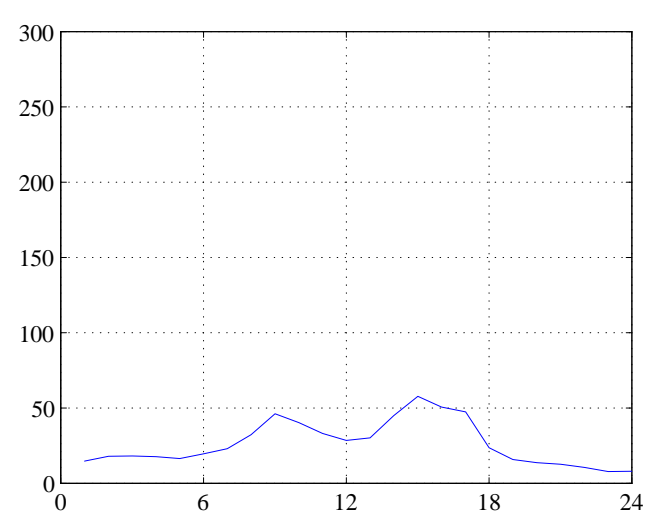


Figure 3: Gross Volumes for CAD, AUD and NZD, hourly across 24-hour clock, GMT time CAD

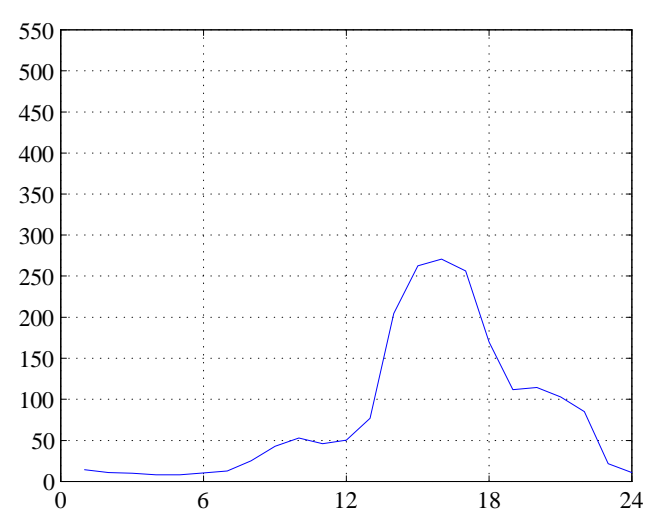

AUD

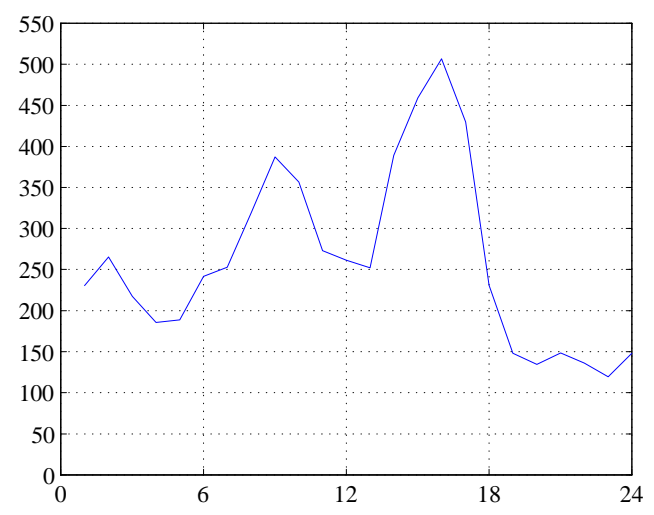

NZD

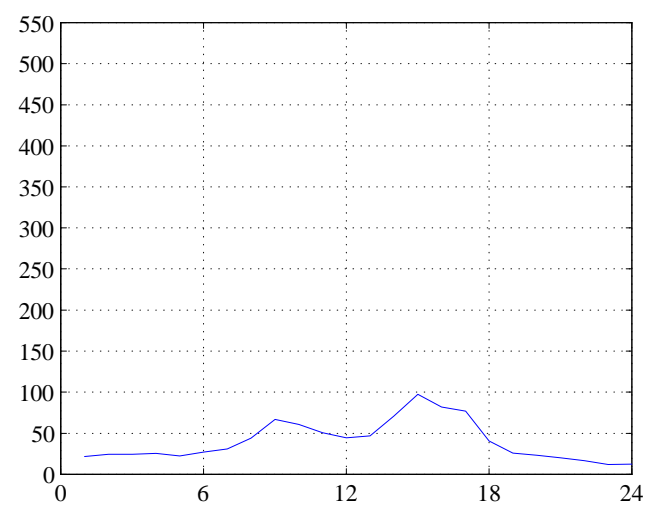


Figure 4: Spreads for CAD, AUD and NZD, hourly across 24-hour clock, GMT time

CAD

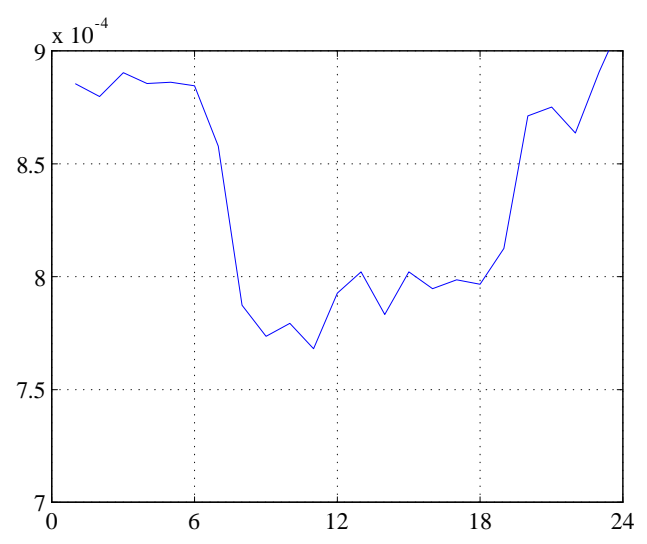

AUD

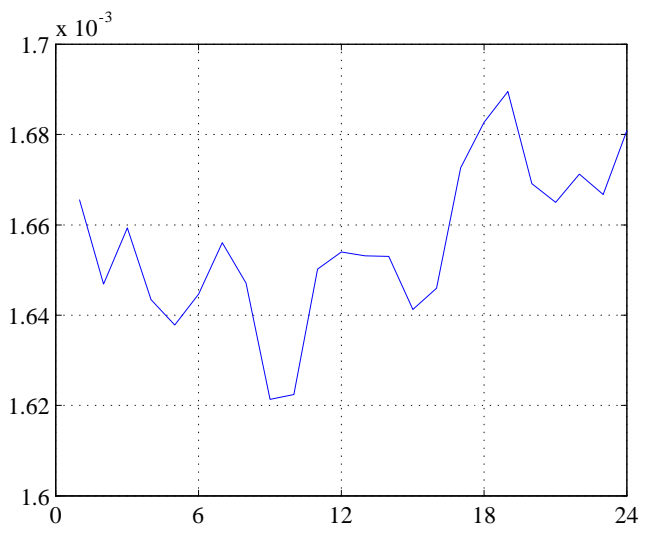

NZD

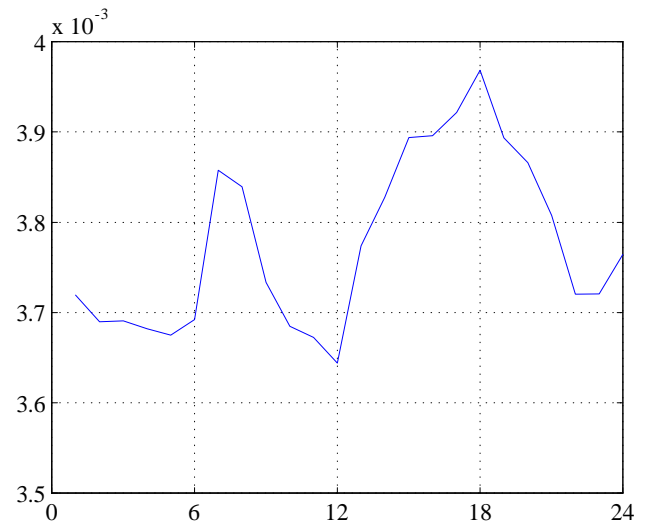


Figure 5: Volatility for CAD, AUD and NZD, hourly across 24-hour clock, GMT time

CAD

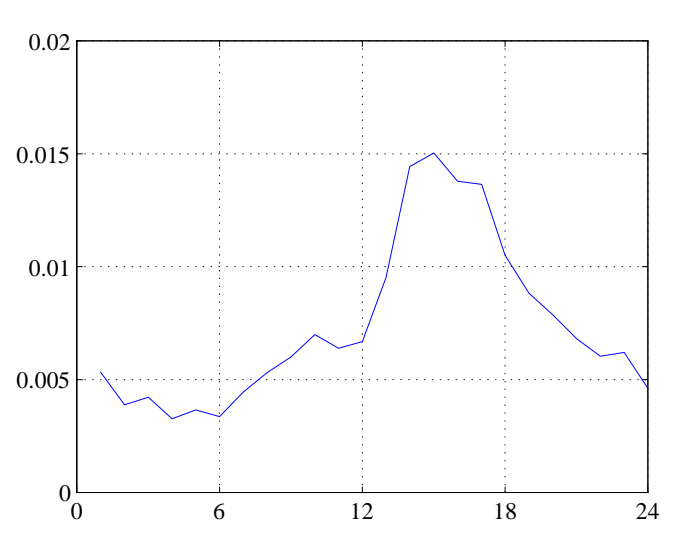

AUD

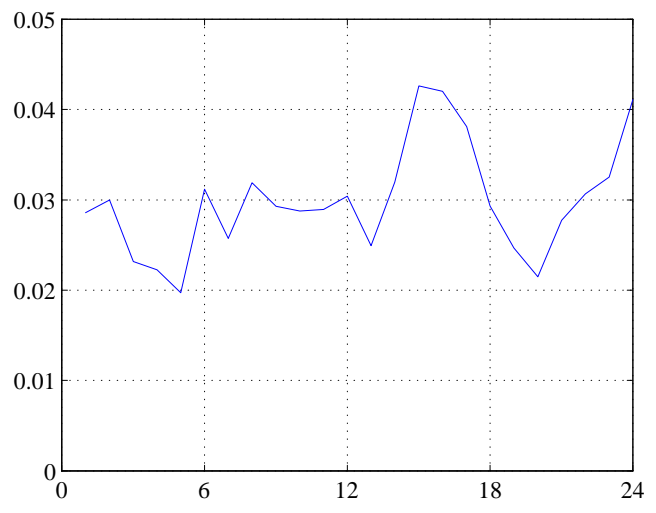

NZD

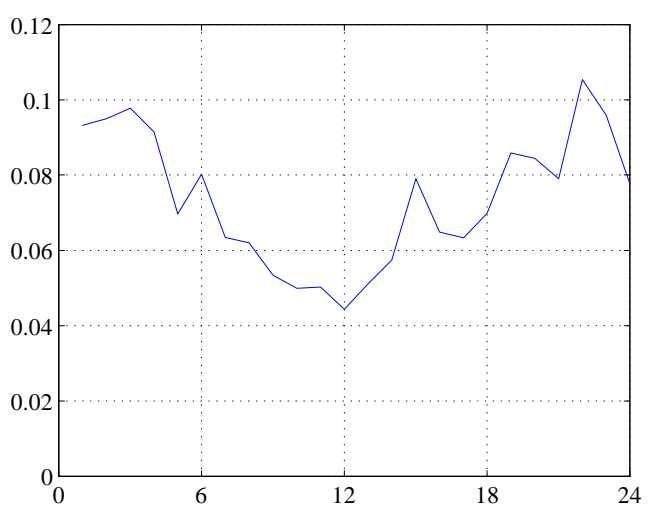

